\title{
Supercritical CO2 Brayton Cycles for Solar-Thermal Energy
}

Brian D. Iverson

Brigham Young University - Provo, bdiverson@byu.edu

Thomas M. Conboy

James J. Pasch

Alan M. Kruizenga

Follow this and additional works at: https://scholarsarchive.byu.edu/facpub

Part of the Mechanical Engineering Commons

\section{Original Publication Citation}

Iverson, B. D., Conboy, T. M., Pasch, J. J., and Kruizenga, A. M., 2013, "Supercritical C02 Brayton cycles for solar-thermal energy," Applied Energy, Vol. 111, pp. 957-970. doi:10.1016/ j.apenergy.2013.06.020

\section{BYU ScholarsArchive Citation}

Iverson, Brian D.; Conboy, Thomas M.; Pasch, James J.; and Kruizenga, Alan M., "Supercritical CO2 Brayton Cycles for Solar-Thermal Energy" (2013). Faculty Publications. 1564.

https://scholarsarchive.byu.edu/facpub/1564 


\title{
Supercritical $\mathrm{CO}_{2}$ Brayton Cycles for Solar-Thermal Energy*
}

\author{
Brian D. Iverson ${ }^{a b+}$, Thomas M. Conboy ${ }^{b}$, James J. Pasch ${ }^{b}$ and Alan M. Kruizenga ${ }^{b}$ \\ ${ }^{a}$ Brigham Young University, UT, 84602 \\ ${ }^{b}$ Sandia National Laboratories, Albuquerque, NM, 87185
}

*Submitted for possible publication in Applied Energy, February 2013

†Author to whom correspondence should be addressed: bdiverson@byu.edu 


\begin{abstract}
Of the mechanisms to improve efficiency for solar-thermal power plants, one of the most effective ways to improve overall efficiency is through power cycle improvements. As increases in operating temperature continue to be pursued, supercritical $\mathrm{CO}_{2}$ Brayton cycles begin to look more attractive despite the development costs of this technology. Further, supercritical $\mathrm{CO}_{2}$ Brayton has application in many areas of power generation beyond that for solar energy alone.

One challenge particular to solar-thermal power generation is the transient nature of the solar resource. This work illustrates the behavior of developmental Brayton turbomachinery in response to a fluctuating thermal input, much like the short-term transients experienced in solar environments. Thermal input to the cycle was cut by $50 \%$ and $100 \%$ for short durations while the system power and conditions were monitored. It has been shown that despite these fluctuations, the thermal mass in the system effectively enables the Brayton cycle to continue to run for short periods until the thermal input can recover. For systems where significant thermal energy storage is included in the plant design, these transients can be mitigated by storage; a comparison of short- and long-term storage approaches on system efficiency is provided. Also, included in this work is a data set for stable supercritical $\mathrm{CO}_{2}$ Brayton cycle operation that is used to benchmark computer modeling. With a benchmarked model, specific improvements to the cycle are interrogated to identify the resulting impact on cycle efficiency and loss mechanisms. Status of key issues remaining to be addressed for adoption of supercritical $\mathrm{CO}_{2}$ Brayton cycles in solar-thermal systems is provided in an effort to expose areas of necessary research.
\end{abstract}

Keywords: supercritical $\mathrm{CO}_{2}$, Brayton, solar-thermal, concentrating solar power, energy 


\section{Introduction}

It is recognized that solar-thermal energy can play a useful role in generating electrical power despite concerns regarding cost, as the thermal source is accessible and ubiquitous. One platform to produce power from a solar resource is using the point-focus, power-tower system in which the solar-thermal energy is concentrated thereby elevating the working temperature and associated efficiencies. Solar assisted power production to offset carbon emissions [1] and thermal storage for grid stability [2-4] remain strong motives for utilizing this approach. Costreduction efforts have been implemented to improve solar-thermal power production [5] with more aggressive efforts being supported by the U.S. Department of Energy [6]. High-efficiency power cycles is a critical component in achieving the cost reduction goals and may require temperatures that reach above $600{ }^{\circ} \mathrm{C}$ to obtain cycle efficiencies in the $50 \%$ range.

The supercritical carbon dioxide $\left(\mathrm{sCO}_{2}\right)$ Brayton cycle has emerged as a promising avenue for high-efficiency power production. With growing interest in renewable energy sources, cycles with high efficiency are critical to achieving cost-parity with non-renewable sources. Convergence on $\mathrm{sCO}_{2}$ Brayton is occurring from the nuclear [7-9] and geothermal [10] fronts, in addition to solar-thermal [11-13]. Turbomachinery for $\mathrm{sCO}_{2}$ Brayton is in the development phase [14-19] and is gaining momentum as interest grows and technical risks are reduced. However, adaptation of the cycle to interface with various heat sources will be imperative for its adoption as an industry-manufactured technology.

Over the past decade, there has been a significant amount of research on $\mathrm{sCO}_{2}$ power cycles and heat transfer. Turbine and compressor performance characterization and prototype system testing has been a primary focus at Sandia National Laboratories (SNL) within the Advanced Nuclear Concepts group [17-23]. System control and transient analysis on $\mathrm{sCO}_{2}$ has been a large focus at Argonne National Laboratory (ANL), specifically for Lead Fast Reactors (LFRs) and sodium-cooled reactors [24-29]. Various cycle configurations have been investigated for specific reactor designs $[8,9,30-33]$. Echogen has considered $\mathrm{sCO}_{2}$ cycles for waste heat recovery, utilizing smaller power systems [34] and views $\mathrm{sCO}_{2}$ as a valid competitor to steam technology [35]. While some work has been done pertaining specifically to solar applications, the literature for $\mathrm{sCO}_{2}$ is introductory by comparison $[11,36]$. The Southwest Research Institute is also active in enabling $\mathrm{sCO}_{2}$ for solar energy and is pursuing turbo-expander and heat exchanger development for this purpose [37].

Interfacing the solar resource with a $\mathrm{sCO}_{2}$ Brayton cycle requires a receiver to absorb the solarthermal energy from the incident concentrated flux and transfer the energy to a transport media. The transport media in the receiver can either be the same as the power cycle working fluid (direct receiver) or employ a secondary media, either fluid or solid, that would experience heat exchange with the power cycle working fluid (indirect receiver). A direct receiver approach can leave the power cycle exposed to potential issues with a transient heat source whereas an indirect approach provides a buffer from transients.

This paper demonstrates the response of a prototype $\mathrm{sCO}_{2}$ Brayton cycle under transient operating conditions similar to that experienced in a typical solar plant with a direct receiver. While the operating conditions of temperature and pressure for the experiments are lower than that desired for high-efficiency operation, this data serves to validate modeling efforts that can be used to evaluate higher-temperature systems. A discussion of primary mechanical and thermal losses is provided as well as areas of advancement required for adoption of $\mathrm{sCO}_{2}$ Brayton turbomachinery for solar applications. 


\section{Experimental Loop}

\subsection{Layout}

The experimental loop installed at Sandia National Laboratories (Figure 1, Table 1) is a split flow recompression cycle. The 'split flow' indicates that two separate turbines receive separate, dedicated flows. These two flow streams are expanded and then recombine after the turbines. A second flow split is located prior to the cooling and compression stages. One stream of the low-pressure flow is 'recompressed' without rejecting heat and is designed to operate at temperatures above the critical point. The main compressor operates near the critical point and the flow stream through this compressor experiences heat rejection. This configuration is expected to have improved cycle efficiency relative to a simple Brayton cycle. First, there is less heat rejection in the pre-cooler resulting in smaller heat loss as only a fraction of the flow passes through this component. Second, the thermal capacities of the hot and cold flows in the low temperature recuperator (LT recuperator) are better matched to optimize heat recuperation [38] with a resulting mass flow ratio of hot to cold that is close to 2:1. This is because the low temperature fluid exiting the main compressor is much closer to the critical point and therefore has a specific heat that is approximately double that of the higher temperature flow. Matching thermal capacities optimizes the heat transfer.

Figure 2a presents the thermodynamic state points for a representative recompression Brayton cycle capable at Sandia. The expansion process from points 5 to 6 is the same regardless of the number of turbines, assuming equal speeds for separate shafts. The final loop design with two separate turbo-alternator-compressors (TAC) was determined, in part, by a staged approach due to anticipated incremental government funding. The modular nature of the design allows for multiple configurations, a feature that enables proprietary and novel configurations by independent institutions.

The thermal input for the system is $780 \mathrm{~kW}$ and was selected based on key control and stability issues of the $\mathrm{sCO}_{2}$ Brayton cycle while small enough to be affordable over several years of development. The main disadvantage of the relatively small size, and the resultant high turbomachinery rotational speeds, is that the system requires bearing, seals and motor alternator approaches that are not necessarily representative of a commercial-scale system. A compromise between fidelity and cost was achieved, while addressing the underlying questions for the technology to reduce risk for future industrial efforts in $\mathrm{sCO}_{2}$ power systems.

\subsubsection{Cycle Components}

A complete description of the major components that constitute the Sandia split flow recompression test assembly is presented in Sandia report SAND2012-9546 [39]. The following is a summary description of the major components.

The TACs are hermetically sealed pressure vessels, rated for the maximum pressure and temperature conditions anticipated in the flow system. Within the vessel, the compressor wheel, gas bearings, and turbine are laid out along the shaft as shown in Figure 3. $\mathrm{CO}_{2}$ enters the compressor on the right hand side of the compressor, and is discharged radially. Likewise, hot $\mathrm{CO}_{2}$ enters down from the top of the turbine, and is expanded radially to the left-hand side of the figure. At design conditions, both turbomachinery wheels are subjected to pressures in excess of the critical point. During operation, leakage flow passes around the compressor and turbine through abradable labyrinth shaft seals to provide lubrication to thrust and journal bearings. The leakage flow is continuously pumped out of this region using scavenging pumps, 
driving a cooling flow and maintaining reduced film pressures (ideally around $1.4 \mathrm{MPa}$ ) in the central cavity surrounding the permanent magnet shaft and bearings.

The split-flow Brayton cycle uses TACs to compress the low-pressure and low-temperature $\mathrm{CO}_{2}$ to a high pressure at the compressors, and then expand the high-pressure and high-temperature $\mathrm{CO}_{2}$ in the turbines. At and near design conditions, the turbines generate more power than the compressors and inefficiencies consume, and the remaining power is used to make electricity in the motor alternator. In the power generation mode, the alternator applies an electrical load to the TACs' rotating shaft that is sufficient to maintain the commanded rotational speed. The applied electrical load represents the power that the TAC would produce for consumer use. TAC-A takes, as input to the compressor, the flow that discharges from the gas chiller, which is the coldest point in the circuit. As such, it is also the least compressible. Therefore, TAC-A consumes less energy per unit mass to compress the fluid than the recompressor in TAC-B.

A single low-pressure flow discharges from the LT recuperator, where it splits into two flow paths, one path to each compressor. The fraction of the total flow going to each compressor is a function of the relative speeds of the two TACs and the thermodynamic state of the fluid at each inlet. These factors combine to determine each compressor's discharge pressure. When the two flows recombine (at the main compressor flow discharge from the LT recuperator) they must be at the same pressure. Pressure mismatch at this point can put a compressor into a potentially damaging state of surge. The primary control to avoid surge is the speed of each TAC, with the magnitude of heat rejection in the gas chiller being of secondary importance. Minimum and maximum rotational speed for each TAC is $25,000 \mathrm{rpm}$ and $75,000 \mathrm{rpm}$, respectively.

A recompression cycle requires two recuperative heat exchangers, referred to here as high temperature (HT) and low temperature (LT) recuperators. The total low-pressure flow exiting the turbine flows through both recuperators, while the total high-pressure flow exiting the compressors flows through the HT recuperator (only the flow exiting the main compressor passes through the LT recuperator). A third heat exchanger is required to reject heat to maintain the system operating point. Heatric printed circuit heat exchangers (PCHE) were selected for all heat exchanger components. The flow passages in PCHE's are etched into 316 stainless steel plates, which are then stacked and diffusion bonded to form the core of the heat exchanger. The resulting components enable an extremely efficient and compact heat exchange. The HT and LT recuperators are designed to transfer $2.3 \mathrm{MW}$ and $1.7 \mathrm{MW}$, respectively. In the recompression configuration, the LT recuperator duty is only $0.6 \mathrm{MW}$. The heat rejection PCHE is rated at approximately $0.54 \mathrm{MW}$, which is sufficient to establish the main compressor inlet $\mathrm{CO}_{2}$ temperature near the critical temperature.

The solar heat source is simulated using electrical resistive heating in six shells through which the $\mathrm{CO}_{2}$ flows. Each of the six immersion heaters provides $130 \mathrm{~kW}$ of heat input, providing a total heating capacity of $780 \mathrm{~kW}$. With these heaters, there is sufficient power to reach temperatures up to approximately $538^{\circ} \mathrm{C}$.

\subsection{Operation}

The primary objective of testing in this work is to achieve steady operating conditions and then observe the system response to perturbations in operating conditions, thereby simulating a transient solar environment. When operating a power cycle in combination with a solar resource, the potential exists that the direct normal insolation (DNI) used to heat the working fluid may decrease drastically during periods of cloud cover. These transients may last for as short as seconds or as long as hours and days. While thermal storage can mitigate the effects of 
drastic transients, usage of thermal storage to level the power output will be dependent on market conditions that drive power plant operation, availability of storage and the short-term forecasting of the cloud transient. Due to diurnal cycling, even without cloud transients, power cycles driven by a solar resource are inherently transient. Stability may be improved through usage of other power sources such as nuclear, geothermal, etc. However, characterization of transient responses is still required for off-normal operation especially as one considers the fluctuations around the $\mathrm{CO}_{2}$ critical point.

Test runs of the recompression Brayton cycle are time-intensive. Test preparation includes evacuating the system over night to near-zero pressure followed by filling with $\mathrm{CO}_{2}$ to the desired mass loading, and then elevating the system temperature from a cold state to the selected steady state operation. The current maximum thermal ramp-up rate is approximately 5 ${ }^{\circ} \mathrm{C}$ per minute. At this rate, increasing the operating temperature from $17^{\circ} \mathrm{C}$ to $477^{\circ} \mathrm{C}$ requires approximately 2 hours. This ramp rate is derived from experience and by piping stress limitations; alternate heating rates and associated designs can be optimized for particular system needs.

In order to simulate the system response to a fluctuating heat source, several test runs were conducted where the heater power settings were reduced by $50 \%$ and $100 \%$. The time periods for $50 \%$ reduced power setting (Figure 4) are from 7012 to 7073 seconds, and from 7349 to 7529 seconds ( 61 seconds and 170 seconds, respectively). The time periods for $100 \%$ reduced power setting (Figure 5) are from 4082 to 4148 seconds, and from 5332 to 5465 seconds (66 seconds and 134 seconds, respectively). Before adjustment of the power setting, the nominal heating power inputs for the $50 \%$ and $100 \%$ cases are $280 \mathrm{~kW}$ and $160 \mathrm{~kW}$, respectively. It is difficult to maintain a perfectly steady state condition prior to transient excursions due to variations in TAC speeds and system cooling, among other perturbations. A best effort was made to establish conditions prior to an excursion that would produce accurate indications of a true system response to simulated solar resource transients.

System response is characterized in four separate plots for each heater power setting reduction, namely: pressure response in the low-pressure and high-pressure legs, temperatures at the heater inlet and discharge, and the system net power generation response. Negative power indicates power production by the system. The large change in net power generation indicated at $4870 \mathrm{~s}$ in Figure $5 \mathrm{~d}$ are due to a controlled reduction in cooling water temperature, which caused the compressor inlet flow to become more dense, less compressible, and therefore requiring less compressor work. The main compressor experienced an increase in mass flow, at the expense of the recompressor, but at a higher density. The greater mass flow at lower compressibility resulted in a roughly net-zero change in power for the main compressor. However, the reduced mass flow to the recompressor resulted in a sharp decline in required compressor power.

The mass associated with the heat input system results in a thermal capacitance effect. Despite changing the heater power setting by a $50 \%$ or $100 \%$ reduction in power, the thermal input to the cycle fluid does not necessarily reduce by $50 \%$ or $100 \%$. Instead, for the $50 \%$ reduction, the thermal input (due in part to thermal capacitance of the piping and heater array) declined to minimum values of $210 \mathrm{~kW}$ in the first excursion, and $200 \mathrm{~kW}$ in the second. This thermal input was determined by using the enthalpy change in the fluid across the heaters and the mass flow rate. For the $100 \%$ power reduction, the thermal input (all due to thermal capacitance) declined to minimum values of $60 \mathrm{~kW}$ and $56 \mathrm{~kW}$ in the first and second excursions, respectively. 
From plots (a) and (b) in Figure 4 and 5, it is apparent that system pressures decline in response to the loss of thermal input. An inherent characteristic of a closed Brayton system is that as the heated cycle fluid increases in temperature and decreases in density during startup, it pushes fluid to the colder components, effectively increasing the whole system pressure. Thus, when the hot side declines in temperature, so too will the system pressure.

The low-pressure leg response to thermal power input reduction is a modest decline, approximately $50 \mathrm{kPa}$ or less. The high-pressure leg response (plot b, Figure 4 and 5 ) is greater, with a maximum reduction approaching $100 \mathrm{kPa}$. Thus, the high-pressure leg responds to thermal input changes with greater fidelity.

The cycle fluid temperature response is presented in plot (c) of Figure 4 and 5 . These plots for the $50 \%$ and $100 \%$ reductions show the temperatures immediately downstream of the power perturbation (heater discharge), and immediately upstream (heater inlet). As one would expect, the temperature immediately downstream shows a much more dramatic and immediate change than the upstream temperature. Downstream and upstream temperature reductions for the $50 \%$ power reductions are $20^{\circ} \mathrm{C}$ and $10{ }^{\circ} \mathrm{C}$ for the first transient, and $35^{\circ} \mathrm{C}$ and $15^{\circ} \mathrm{C}$ for the second transient. The corresponding upstream and downstream temperature reductions for the $100 \%$ power reductions are $40^{\circ} \mathrm{C}$ and $10^{\circ} \mathrm{C}$ for the first transient, and $50{ }^{\circ} \mathrm{C}$ and $15^{\circ} \mathrm{C}$ for the second transient. The upstream response is muted and delayed for several reasons. First, there is a finite period of time required for the fluid to transit the loop. The fluid that is immediately affected in the heater requires that transit period to return to the heater inlet. Second, the recuperators inherent in the design of a recompression system act to mitigate the sharpness and magnitude of thermal changes in the cycle. Finally, the thermal capacity of all piping and components acts to delay the magnitude of a thermal transient.

In general, the various responses in the pressure, temperature and power output to the reduction in thermal power input exhibit an exponential decay, indicative of what is expected from stored thermal energy in a thermal capacitor. System response after the heating power is restored exhibits a complementary logarithmic rise. These trends are best displayed in the temperature histories in plot (c). When solar transients do occur, short perturbations of this type can easily be managed by thermal capacitance in the system with the extent of the exponential decay in system variables dependent on the total thermal mass and heat losses inherent in the heating system.

\subsection{Measurement Uncertainty}

A particular test case and operating conditions was selected for consideration of system losses and measurement uncertainty. A data point $7600 \mathrm{~s}$ into the test was selected from Figure 4 and analyzed at a time of steady power generation (see also Table 2).

\subsubsection{Thermal Loss}

Thermal losses between two separate locations in the cycle can be assessed by examination of temperature change across lengths of piping that are not directly heated or cooled as part of a cycle process. This is most significant along the high-temperature legs of the system. These segments are larger in diameter and are of considerable length to accommodate thermal expansion. The loop structure continues to be developed and is largely not insulated. This is responsible for a significant amount of the poor system performance from the standpoint of total system efficiency, providing context to discrepancies between theoretical and experimentally observed cycle characteristics. 
Figure 1 indicates the locations of significant heat loss. Heat losses are estimated in these regions by a product of mass flow, heat capacity, and temperature change. For the selected test condition at $7600 \mathrm{~s}$ (Table 2), $62.3 \mathrm{~kW}$ of heat is lost from the HT recuperator to the heater inlet, $40.9 \mathrm{~kW}$ is lost upstream of the turbines, and $10.5 \mathrm{~kW}$ is lost from the turbine outlet legs to the HT recuperator inlet. Losses at the turbine volute are also noted to be $8.8 \mathrm{~kW}$ and $7.5 \mathrm{~kW}$ for turbines $A$ and $B$, respectively. Volute thermal losses are estimated from known conditions at the inlet and outlet of the turbine, and turbine performance maps for a given set of conditions [40]. The discrepancy between measured turbine outlet conditions, and outlet conditions predicted by the performance map is attributed to a cooling mechanism at the back of the turbine volute due to rapid expansion of high pressure $\mathrm{CO}_{2}$ across the rotating seal, into the lowpressure alternator housing. In total for this test case, $130 \mathrm{~kW}$ is lost to various thermal mechanisms for a heater input of $342 \mathrm{~kW}(38 \%)$.

\subsubsection{Losses to Rotating Friction}

Rotating loss, or windage, is also a significant contributor to conversion inefficiencies for the current test assembly. The high-speed environment, along with high density and low viscosity, generate a highly turbulent environment at the shaft and within tight clearances of the gas foil thrust and journal bearings. The presence of turbulence causes a sharp increase in the dependency of frictional loss and load capacity to environmental conditions, namely a heightened sensitivity to lubricant gas pressure and runner speed. This phenomenon was first observed in testing of journal bearings at NASA's Glenn Research Center [41]. Intensive frictional losses not only serve as a parasitic load, but also can cause extreme local heating of bearings and other turbomachinery internals, causing turbine malfunction.

Modeling TAC windage has revealed that the major loss is due to the shaft itself and the thrust bearing assembly; these combine for upwards of $85 \%$ of frictional loss [38]. The two radial bearings account for the remainder. These estimates are based on consideration of the turbomachinery assembly as a simplified series of tightly-housed concentric cylinders and disks and applying friction relations for turbulent boundary layers by Schlichting [43] and Vrancik [44]. Figure 6, illustrates the relative contribution of windage loss (based on these turbulent correlations) for the journal bearings, thrust bearing and rotating shaft. The sum of these power losses is also provided in the figure. Ongoing work seeks to optimize the thrust bearing assembly for reduced friction and resistance at higher temperatures without compromising load capacity. This is the primary challenge in attaining high speeds approaching $75 \mathrm{krpm}$ for the current test assembly.

To isolate and quantify empirical rotating losses for the present test assembly, a series of tests was conducted to identify the net contribution of the windage losses (illustrated in Figure 6) plus that due to seals. This total rotating loss was measured by removing the turbine and compressor wheels from the shaft, and recording the resultant power consumption required to spin the bare shaft alone at high speeds within prototypic $\mathrm{CO}_{2}$ environments. Sensitivity to $\mathrm{CO}_{2}$ properties, shaft speed, and thrust loads were evaluated directly [42]. CFD modeling of the $\mathrm{sCO}_{2}$ lubrication layer was also undertaken to confirm that observed losses were consistent with turbulent theory. The resulting correlation for power loss that scales with angular velocity $(\omega)$ and fluid properties (density $\rho$ and viscosity $\mu$ ) is as follows:

$$
P_{\text {turb }}=0.155 \omega^{2.8}\left(\frac{\rho}{21.1\left[\mathrm{~kg} / \mathrm{m}^{3}\right]}\right)^{0.8}\left(\frac{\mu}{14.9[\mu \mathrm{Pa} \cdot \mathrm{s}]}\right)^{0.2}
$$


Equation 1 can be used for estimating windage losses in test data within $+/-5 \%$ for speeds less than $50 \mathrm{krpm}$. This correlation runs approximately $20 \%$ higher than that predicted by turbulent theory (Figure 6) for rotating disks and cylinders alone [42]. This can be attributed to the simplified modeling approach and neglect of shaft seals. Empirical testing results yielding equation 1 indicates an estimated $4.9 \mathrm{~kW}$ loss for turbine $A$, and $10.1 \mathrm{~kW}$ loss for turbine $B$. The difference between $A$ and $B$ in this case is due to their speed differential at $7600 \mathrm{~s}$ and fluid properties in the rotor housing. Here, $\mathrm{CO}_{2}$ properties of density and viscosity are taken within the turbine housing, where the shaft and gas bearings operate. Typical temperatures and pressures in the rotor housing are $150{ }^{\circ} \mathrm{C}$ and $1.4 \mathrm{MPa}$.

\subsubsection{Leakage Flows}

At each turbine and compressor wheel, leakage flow bypasses the rotating element in the housing through abradable labyrinth shaft seals and into the turbine housing where the gas bearings and alternator spin in a reduced pressure environment (Figure 3). The leakage flow critically provides bearings with a hydrodynamic film for load support and transfers frictional heating. A gas scavenging system pulls $\mathrm{CO}_{2}$ from the housing to prevent buildup of pressure, driving a cooling flow through the turbine, and pumps it back into the high pressure loop to complete the closed cycle. A supplementary bypass line connects from the compressor inlet at each TAC unit and penetrates into the turbine housing in the vicinity of the high temperature turbine-end radial bearing. This additional cooling is metered by a manual needle valve along the flow path.

The combination of leakage flow in the seals and bypass flow for cooling bearings is considered the total system leakage flow. The mass flow, temperature and pressure of this flow is measured and considered in the data reduction process as follows. During the compression stage, leakage flow in the seals is included in the compressor work calculation, since it is judged that the flow cannot reach the seals without first passing the through the centrifugal wheel. During expansion, leakage flow is not included in the turbine work calculation, since the leakage flow largely bypasses the turbine wheel.

The current approach for seals limits leakage flow to less than $5 \%$. Consequently, the impact to compressor and turbine work calculations is minimal, but can still represent up to $5 \%$ of unrecoverable loss. Given the nature of abradable seals and the small-scale geometry of the present rotating hardware, this flow rate may change somewhat over time for a fixed set of $\mathrm{CO}_{2}$ conditions upstream of the seal, as the labyrinth seal experiences wear. For this test on $9 / 11 / 2012$ near 7600 seconds, the total mass flow topped $3.5 \mathrm{~kg} / \mathrm{s}$ while leakage flow was 0.1 $\mathrm{kg} / \mathrm{s}$ in total, or $2.8 \%$.

\subsubsection{Uncertainty Analysis}

Analysis of net power generation requires knowledge of compressor and turbine work (as measured by enthalpy change across each active component), and estimated thermal and frictional losses. Each has associated uncertainty. For the compressor and turbine evaluations, calculations depend on measurements of mass flow and enthalpy change across the component of interest. Using an in-house data reduction and analysis code, enthalpy is evaluated by using the RefProp [45] property tables based on local temperature and pressure at the inlet and outlet of each component. An exception to this is that measured density is used for the enthalpy calculation at the compressor inlet, which is near enough to the saturation region that temperature and pressure alone cannot be relied upon. 
Uncertainty $(U)$ in compressor work, for example, can be calculated based on partial derivative of work $(W)$ with respect to each input into the calculation $\left(x_{i}\right)$, using the following relative instrument uncertainties: temperature $+/-1 \%$, mass flow $+/-4 \%$, pressure $+/-5 \%$, and density $+/-$ $1 \%$.

Propagation of uncertainty was carried out by evaluating each partial derivative and combining them as shown in Equation 2.

$$
U_{W}=\sqrt{\sum_{i=1}^{n}\left[\left(\frac{\partial W}{\partial x_{i}}\right)^{2} U_{x_{i}}{ }^{2}\right]}
$$

For the particular test in Figure 4 (at $7600 \mathrm{~s}$ ), each turbine work uncertainty was calculated with measured uncertainties to be $2 \%$. The main compressor work, which operates nearest to the critical point, also exhibited an uncertainty of $2 \%$, while the recompressor work is accurate to within $4 \%$.

\section{Cycle Modeling}

A Fortran model of the Sandia split flow recompression Brayton cycle has been developed to investigate performance trade-offs and inform improvement decisions. The inputs to this model include main compressor inlet pressure and temperature, speeds for both TACs, and heater discharge temperature. Digital versions of the turbomachinery performance curves are interrogated, which requires an iterative approach to resolving a balanced steady state condition. Pressure losses throughout the loop are based on curve fits of experimental component pressure losses as a function of mass flow. Using these five inputs, a balanced operating point is obtained that defines the state points around the system, and component and system performance.

An assessment of the model fidelity relative to measured data was calculated. A significant challenge in applying this model to current test data is that the main compressor in TAC-A has been replaced with a recompressor wheel, which is designed to operate at conditions that the TAC-B recompressor wheel experiences. The primary difference is the inlet temperature. The recompressor wheel is designed for inlet temperatures approximately $28^{\circ} \mathrm{C}$ higher than that entering the TAC-A compressor. The result of operating the recompressor at much lower temperatures than design is significantly reduced accuracy when interrogating the recompressor performance maps. Thus, predictions from the model in the vicinity of the TAC-A recompressor deviate from test data. Stated succinctly, fairly significant deviations between data obtained to date and model predictions are to be expected. Additional efforts to improve this prediction are underway and will come largely from expanding the envelope of speed, temperature, pressure, and power production experience.

In Table 2, the 'Measured' column presents the state points and resulting cycle performance at $7600 \mathrm{~s}$ into the test run from Figure 4 on 9/11/2012 and serves to compare actual system performance with predictions from the model of the test assembly including turbomachinery performance calculations based on boundary conditions. Table 2, column 'Calculated (a)' presents model predictions using actual test data measurements as inputs for only the five input parameters above. Comparison of the state points throughout the loop as well as the cycle performance parameters show good agreement and are adequate to have confidence in 
extrapolating to different operating conditions. In particular, the predicted cycle efficiency is $6.2 \%$ at a measured efficiency of $5.3 \%$.

Table 2, column 'Calculated (b)' is the model prediction output for the original design conditions of Sandia's recompression Brayton cycle. In this model run, the main compressor wheel has been installed and model input values have been set to the design conditions. Therefore, these predictions are expected to reliably predict the performance of the current loop. The original expectation for design performance included approximately $250 \mathrm{~kW}$ of electricity at an efficiency of about $32 \%$. However, the model predicts $135 \mathrm{~kW}$ and a cycle efficiency of $15.2 \%$. The deviation between original design performance and the predictions listed under the column labeled 'design' are directly attributed to heat loss, leakage and windage that were excluded from original design predictions. In addition, actual pressure losses throughout the system have been found to be greater than the original design pressure losses.

Thermal losses occur in the turbine housing, driven by the temperature difference between the hot turbine inlet volute and the water-cooled alternator compartment immediately adjacent to the turbine volute. Temperatures in the alternator volume are typically on the order of $100^{\circ} \mathrm{C}$ or less. This is dramatically lower than the turbine inlet temperature, with a separation of only a few centimeters. This situation causes a large temperature gradient that drives thermal conduction losses from the turbine volute. The fluid temperature at the radial turbine wheel inlet is not currently measured. However, an attempt is made to quantify this loss by reducing the temperature used to interrogate the turbine performance curves until the predicted discharge temperature is sufficiently close to the measured discharge temperature. It is for this reason that the temperatures for points $5 \mathrm{~b}-\mathrm{A}$ and $5 \mathrm{~b}-\mathrm{B}$ in the 'Measured' column are about $4{ }^{\circ} \mathrm{C}$ less than the adjacent 'Calculated (a)' column in Table 2.

Columns 5 and 6 in Table 2 present model predictions for the same design system, but with accumulating improvements to the system. These include installation of insulation to eliminate thermal losses ('Calculated (c)'), and an improvement in compressor design to obtain efficiencies in the mid $80 \%$ range ('Calculated $(d)$ '). With both of these improvements simulated, the model predicts power production of $172.6 \mathrm{~kW}$, and a gross efficiency of $24.1 \%$. Continued improvements can be predicted assuming reduction of other losses, such as leakage flows, windage, and pressure losses.

Other potential improvements to the cycle including raising the design temperature and pressure are possible. Currently, the installed system is limited by the maximum design temperature and pressure ratio of $538^{\circ} \mathrm{C}$ and 1.8 , respectively. A Brayton cycle designed to operate with a solar energy source can operate at temperatures in excess of $600{ }^{\circ} \mathrm{C}$ with pressure ratios on the order of 2.5. These changes greatly increase the thermal to electric conversion efficiency, and will likely yield efficiencies in the vicinity of $50 \%$ as is commonly cited [46].

\section{Advances for $\mathrm{SCO}_{2}$ Brayton adoption}

There are a number of technical challenges that require attention for $\mathrm{sCO}_{2}$ Brayton adoption in solar-thermal power generation. They include a significant amount of work in development of turbines, bearings, seals, heat exchanger design (especially when considering salt to $\mathrm{sCO}_{2}$ heat exchange) and materials. The following outlines several of the needs associated with this technology adoption and are addressed here in an effort to provide a realistic view regarding the path to implementation as well as a projection of plant cost. 


\subsection{Turbine development}

Several improvements in the Brayton turbomachinery could significantly improve the efficiency by reducing losses. A $10 \mathrm{MW}_{\mathrm{e}}$ system size has been identified as the minimum needed for demonstration of commercial-scale turbomachinery technology for $\mathrm{sCO}_{2}$ [47]. Whereas the present test assembly uses radial compressors and turbines, a $>10 \mathrm{MW}_{\mathrm{e}} \mathrm{sCO}_{2}$ power system would be a multi-stage axial machine much like present-day industrial gas turbines. The 10 $\mathrm{MW}_{\mathrm{e}}$ size would also allow for high efficiency at rotational speeds on the order of $24,000 \mathrm{rpm}$, in comparison to the current $75,000 \mathrm{rpm}$ system. This reduction in design speed to $24,000 \mathrm{rpm}$ would allow the turbine to be mated with gear reduction to $3,600 \mathrm{rpm}(60 \mathrm{~Hz})$ using a commercially-available gearbox and allow for synchronous operation similar to commercialscale power systems.

A significant drawback of the current design is that a simultaneous high-speed and highpressure environment at the rotor can cause disproportionately large frictional losses. Also for this small-scale hardware, mere inches separate the high temperature turbine inlet (potentially up to $540^{\circ} \mathrm{C}$ ) from the motor/generator cooling water flow at room temperature, resulting in

thermal losses. Leakage flow bypasses the turbomachinery wheels to lubricate the gas bearings, reducing productive work as well. To manage leakage flows, the turbine itself and other turbomachinery internals must be designed and built to tolerances on the order of thousandths of an inch. All loss mechanisms would be eliminated or greatly reduced for a commerical-scale (multi-MW ${ }_{\mathrm{e}}$ ) Brayton system [47].

Additional objectives include demonstration of high conversion efficiency and control concepts of the $\mathrm{sCO}_{2}$ closed Brayton cycle. The current split flow recompression turbomachinery will be used to investigate system control algorithms for a recompression cycle. Variables of particular interest include responding to heat input variations, changes in load demand, and responding to emergency events. Primary control features will include turbomachinery speed, heat rejection, and possibly circuit mass loading. Developing control algorithms is necessary to maintain a recompression cycle at optimum performance with automatic controls to respond to various transients such as load demand and heat input. The current research and development system requires continual oversight to maintain the system in a stable condition.

\subsection{Heat exchangers}

When targeting high-capacity factors, a secondary thermal transport media for use in the receiver and storage system (indirect system) is a likely approach given the high pressures associated with supercritical working fluids and low specific heat values for gases. In this indirect system, the primary fluid is defined as that employed by the power cycle and the secondary fluid as that used for collection and/or storage. An indirect approach with different receiver and power cycle fluids allows the media used in each subsystem to be optimized for their specific function in the cycle components. This approach has an additional benefit of being applicable to a variety of power cycles, as the collection and power cycle media are decoupled. However, this requires a heat exchanger at the interface of these subsystems.

An important consideration relative to indirect systems is the ability to incorporate significant energy storage. In instances where capacity factors are relatively low (25\%-50\%), a direct receiver approach, which incorporates heat exchange to a storage media, can be beneficial because the majority of annual energy generation occurs with the heat-transfer media being sent directly to the power block without the incurred losses in a heat exchanger. For largercapacity factors, where a significant fraction of the collected energy is sent to storage, it is more 
efficient to match the storage and receiver media, thus, requiring only a single heat exchanger to interface with a separate power block working fluid (see Figure 7). For the calculations in Figure 7 based on a turbine inlet temperature of $700{ }^{\circ} \mathrm{C}$ and a $98 \%$ storage efficiency, the firstlaw efficiency for an indirect liquid receiver is higher than the direct approach, above approximately ten hours. The crossover in second-law efficiency occurs at a lower storage capacity of approximately seven hours. While this amount of storage capacity may appear to be higher than desired in some energy markets, the cost and feasibility of storing supercritical fluids that reach goals applicable to SunShot would prove cost-prohibitive for both large- and small-capacity factors [48]. Further, the effects of thick-walled piping and a potential slower start-up due to a larger thermal capacitance in system components has been neglected for the direct $\mathrm{CO}_{2}$ approach, further justifying an indirect approach, especially for large capacity factors.

In order to successfully implement an indirect system for solar, a heat exchanger to transfer heat between the dissimilar fluids is necessary. Of the heat exchanger designs to consider, a diffusion bonded heat exchanger (such as a PCHE or hybrid-PCHE $[49,50]$ ) is a possible candidate as the diffusion bonding process is capable of producing small channel sizes that enables containment of the high pressures required for the supercritical phase $[51,52]$. A reduction in the channel hydraulic diameter also enables an increase in the heat transfer coefficient, as they are inversely related $\left(h \sim 1 / D_{h}\right)$. Thus, the small channel size accommodates the two major requirements for heat exchange with $\mathrm{sCO}_{2}$.

On the salt side of the heat exchange, the same channel dimensions used for $\mathrm{sCO}_{2}$ are not optimal due to the concern for plugging of solidified salt. Therefore a hybrid construction using techniques other than printed circuit methods may be required for salt applications [53]. When selecting salts that have higher operating temperatures, typically this also involves a corresponding increase in the melt temperature, making solidification problematic at temperatures well above ambient. Similar concerns exist for sodium in PCHEs, with initial investigations recently appearing $[33,54,55]$. One mitigation strategy is simply to utilize the salt only in a thermal environment where the temperatures never reach solidification temperatures. This is possible for recuperated Brayton cycles where the heat addition from an external source is expected to raise the temperature from 531 to $700^{\circ} \mathrm{C}$ [30]. Common chloridebased salts (e.g., $\mathrm{KCl}-\mathrm{LiCl}-\mathrm{NaCl}$ ternary eutectic melts at $346{ }^{\circ} \mathrm{C}$ [56]) or carbonates typically have melting temperatures well below this range. Start-up procedures, however, may need to involve external thermal input for preheating before salt introduction.

The $\mathrm{sCO}_{2}$ Brayton cycle is known to be highly recuperative, with projected capital costs of heat exchangers representing $80 \%$ of the total cost of the cycle $[31,57]$. Highly compact, efficient heat exchangers are, therefore, necessary for power block cost reduction with numerous design and characterization studies in the literature [58-71]. However, there is very little information on heat exchanger design when considering exchange with a secondary hot working fluid, such as liquid metals or molten salts $[54,68]$. When considering liquid sodium on the hot side, initial studies have only begun to understand conditions under which freezing conditions may occur [54]. The implementation of a salt-to- $\mathrm{SCO}_{2}$ heat transfer interface must address the differential pressure between the hot and cold fluid which may be as high as 20-25 MPa at temperatures of $600-800^{\circ} \mathrm{C}$; not a trivial matter. Idaho National Laboratory (INL) has initiated work relative to using salt-service heat exchangers to link a $\mathrm{SCO}_{2}$ Brayton cycle to a nuclear reactor. Preliminary studies for fluoride salts indicate that shell-and-tube (helical coil) and PCHE heat exchangers are the most likely to achieve the desired results for their advanced high-temperature reactors [51, 52], with the PCHE option preferred for its thermal and structural performance. Further, they 
demonstrated diffusion bonding for nickel-based alloys Haynes $\mathrm{N}$ and 242, despite the high chromium content in these materials resulting in protective oxide layers [49]. Argonne National Laboratory has initiated sodium-to- $\mathrm{SCO}_{2}$ heat exchanger studies with plans to test fill and drain operations to avoid channel blockage [53].

In solar plants where molten salt is the industry standard, it has been long known that molten salts (nitrates and halides) tend to preferentially dissolve and deposit active alloying elements, (e.g. chromium or molybdenum [72-76]), which would need to be addressed for smaller channels where plugging could be an issue [75]. By forcing the salt toward a reducing condition, corrosion becomes extremely slow and may sufficiently inhibit this behavior [77]. $\mathrm{sCO}_{2}$ corrosion of metals is currently being investigated by several institutions with stable oxides (chrome and nickel oxides, and alumina) as protective barriers [78]. It has been found that high concentrations of chromium and nickel significantly increase the corrosion resistance of steel alloys in $\mathrm{CO}_{2}$ [79]. Current studies include investigations of protective layers exposed to impurities and developing protective barriers [80].

\subsection{Bearings/seals}

To date, the approach to gas bearings and seals for this system has demanded a disproportionate amount of the total research effort. The closed cycle, small-scale turboalternator-compressors developed for the present demonstration loop are a result of custom fabrication, and an iterative design and testing process. This has resulted in a system capable of supporting the necessary thrust loads, on the order of $400 \mathrm{~N}$, at high speeds, within minimal irreversible losses. However, there is still considerable room for improvement. Modeling results indicate that a bearing with smaller diameter and fewer thrust pads could maintain thrust load capacity with reduced frictional losses. In addition, incorporation of geometric features (e.g. chevrons) at the trailing edge of each thrust pad to expel hot fluid would likely increase load capacity by enhancing the thermal wedge effect, while improving thermal management [81]. Experimental work has also demonstrated that using a stamped manufacturing approach rather than assembling the thrust bearing manually from many small pieces can attain tighter engineering tolerances. Smaller engineering tolerances allow for operation at reduced film thicknesses, increasing load capacity.

Finally, it is recommended that shaft and thrust runner of next generation $\mathrm{CO}_{2}$ gas bearings be plasma sprayed with a solid lubricant while using bare pads. This improvement is directed at increasing the temperature resistance of the current model, which cannot be heated beyond the dissociation temperature of Teflon.

Commercial-scale systems would apply a different approach to bearings and seals. These systems would almost certainly be large enough to operate efficiently at $3600 \mathrm{rpm}(60 \mathrm{~Hz})$, eliminating the feasibility of high-speed gas bearings. A commercial generator would be located outside of the high pressure $\mathrm{CO}_{2}$ region, likely by using dry liftoff seals to separate the rotor from ambient conditions. Industrial dry liftoff seals use several stages and a buffer or purge gas to isolate the working fluid from the environment, resulting in reduced friction from the present assembly, and use of standard oil-lubricated industrial bearings types.

\subsection{Materials}

Material requirements for thermal solar power applications vary widely depending on the heat transfer fluids under consideration and operating conditions imposed. Focus here will briefly discuss the material requirements of $\mathrm{CO}_{2}$, oxoanion salts (nitrate/nitrite and carbonate), and 
halide anion salts (fluorides and chlorides) that could be used as primary or secondary heat transfer fluids depending on the receiver, power cycle and thermal storage subsystem configurations. Nitrate/nitrite salts are currently used in commercial solar applications, but there is concern with the thermal stability above $600^{\circ} \mathrm{C}$, thus other fluids must be considered for higher temperatures. Carbonates and halides have also been selected for consideration based on their high temperature stability and cost.

Materials with the ability to form passivated oxide layers, such as a chrome oxide or alumina, have been found to perform well with $\mathrm{CO}_{2}[78,82]$. Quantification of the presence of impurities (e.g. moisture) and their role in exacerbating corrosion is necessary for long-term power plant operation [82]. While it is understood that an aggressive attack on containment materials will occur in the presence of impurities there are no well-defined limits that currently exist.

Oxoanion salts, specifically molten nitrate/nitrites and carbonates, have different material considerations than that of $\mathrm{CO}_{2}$. It has been observed that nitrate/nitrite salts and carbonate salts are able to form and maintain passive oxide barriers that are thermodynamically stable in the melt, which as act as diffusion barriers that form following typical parabolic growth rates $[83,84]$. In contrast to $\mathrm{CO}_{2}$, active alloying elements, such as chromium, are soluble in the melt. Corrosion enhancing impurities typically take the form of chlorides, which act to disrupt passive layers and act as a catalyst for corrosion and must be considered from a systems engineering standpoint [85-87]. Thermal decomposition of oxoanion salts into oxides will increase the basicity which, in turn, changes the thermodynamic state of the melt. This decomposition is reflected in potential-oxide (E-pO2-) diagrams (which parallel Pourbaix diagrams for aqueous solutions) and indicates potentially stable phases within the melt, useful in predicting phases that may be used as a protective oxide layer [88]. Questions related to evolved oxide content over time (i.e. thermal decomposition of a given salt) for the long-term stability of the salt need to be addressed, in addition to techniques of online monitoring of salt chemistry.

Halide salts differ significantly from oxoanions in that they do not form passive oxide layers, as is the case with chlorides [89] and fluorides [90-93]. In the case of fluorides, a metal fluoride is more stable than the metal oxides. Alloy protection with fluorides must rely on thermodynamic equilibrium between alloys [94] and this approach has largely been used with chloride melts.

Due to the lack of a diffusion barrier, corrosion-enhancing impurities in halides take the form of oxygen or oxygen containing molecules, such as water or air $[95,96]$. Systems' where initial salt purity and ullage gasses are not controlled experience severe corrosion [77, 97]. Systems' using these salts requires monitoring and purification systems in order to control corrosion of containment vessels. Questions are still outstanding related to chloride systems as to the practical development of thermodynamically and kinetically favorable oxide barriers that might lessen requirements of salt purity, which may preclude the need for a pressure vessel in potential system designs. Information on corrosion rates are incomplete and poorly controlled in many studies, this lack of information on the kinetics of corrosion will be required from a systems standpoint.

Diurnal cycling within a CSP plant places an increased emphasis on materials resistance to cycle fatigue failure. Studies on heat exchangers, for nuclear applications, have focused on the overall strength making alloy 617 a logical choice $[98,99]$. The introduction of thermomechanical stress in a CSP facility motivates evaluation of low cycle fatigue (LCF) properties. Haynes 230, a nickel alloy with high tungsten content, has excellent fatigue life characteristics. As a comparison, Haynes 230 has been observed to fail around 50,000 cycles at $760^{\circ} \mathrm{C}$, while 617 fails around 
15,000 cycles [100]. This is a dramatic difference and will be important for selection in high temperature receiver materials at a minimum for the next generation of solar power plants.

\subsection{Impact on cost goals}

Comprehensive, critically reviewed costing data for the major components of a commercial sized ( $10 \mathrm{MWe}$ ) recompression, closed-Brayton cycle for CSP applications were not found in the open literature. Private parties interested in developing components consider costing data proprietary. To fill this cost information void, Sandia National Laboratories, Oak Ridge National Laboratory (ORNL), and the Department of Energy (Office of Nuclear Energy) are initiating research into these various costs. The result of this effort is intended to be a modeling tool that predicts the levelized cost of electricity (LCOE) for these systems and incorporate the information into the current LCOE program that ORNL maintains. As the working fluid operates in the supercritical phase, the turbomachinery size [35] and cost may be lower but extensive recuperation will necessitate costly heat exchange.

Assuming similar power block costs as that for steam-Rankine, the estimated impact of the proposed Brayton cycle to achieve SunShot goals is assessed using the National Renewable Energy Laboratory's System Advisor Model (SAM, https://sam.nrel.gov/). Assuming a molten salt power-tower plant model and adjusting the power block efficiency (54\% gross) and receiver temperature $\left(700{ }^{\circ} \mathrm{C}\right.$ salt) to account for an indirect, dry-cooled, $\mathrm{sCO}_{2}$ Brayton cycle, the LCOE for a $100 \mathrm{MW}_{\mathrm{e}}$ system has been estimated. In order to achieve $6 \mathrm{c} / \mathrm{kWh}$ (real), a solar multiple of 3.1 and 16 hours of storage is required for the following SunShot-driven system:

- Cost assumptions: site preparation $=10\left[\$ / \mathrm{m}^{2}\right]$, solar field $=75\left[\$ / \mathrm{m}^{2}\right]$, power plant $=1,160$ $[\$ / \mathrm{kW}]$, tower/receiver $=150\left[\$ / \mathrm{kW}_{\mathrm{t}}\right]$, thermal storage $=15\left[\$ / \mathrm{kW}_{\mathrm{t}}\right]$, contingency $=0 \%$, indirect (sales tax and land) $=17.8 \%$, interest during construction $=6.0 \%, 0 \& \mathrm{M}=40$ $[\$ / k W y r]$.

- SunShot financial assumptions: discount rate $=5.5 \%$, inflation rate $=3 \%$, debt rate $=6 \%$, state income tax $=5 \%$, return on equity $=15 \%$, debt fraction $=62 \%$, federal tax $=35 \%$, depreciation $=5 \mathrm{yr}$ MACRS, ITC $=0 \%$.

Of particular note are the large solar multiple and 16 hours of storage required to achieve the desired SunShot LCOE target. This results in a capacity factor of $73.1 \%$ and is in the range that a direct $\mathrm{CO}_{2}$ receiver/system cannot efficiently provide (see Figure 7). Capacity factors of this magnitude must use the storage media in the receiver, thereby requiring liquid-to- $\mathrm{sCO}_{2}$ heat exchangers of the type pursued in this proposal for implementing $\mathrm{SCO}_{2}$ Brayton to capitalize on the cycle efficiency benefits.

\section{Conclusions}

The $\mathrm{sCO}_{2}$ Brayton cycle has been shown to have significant efficiency benefits especially as solarthermal power plants increase their operating temperatures above $600^{\circ} \mathrm{C}$. In particular, part heat load operation, common to a solar resource, appears manageable especially for short durations (e.g. short-term cloud cover) due to thermal capacitance in the system and piping. Therefore it is recommended that $\mathrm{sCO}_{2}$ Brayton cycles continue to be pursued for solar-thermal energy applications.

Thermal, rotational and mass losses for this prototype cycle have been quantified and utilized to benchmark a cycle model with good agreement. Measurement of the system performance 
indicates an efficiency of approximately $5 \%$ for the operation conditions selected in this work. At design conditions, this efficiency is expected to increase to $15 \%$ using the benchmarked model presented in this work and would approach approximately $24 \%$ with minor modifications to improve insulation.

Predicted efficiencies still far short of the $50 \%$ thermal efficiencies claimed for $\mathrm{sCO}_{2}$ at a $600{ }^{\circ} \mathrm{C}$ turbine inlet temperature. This is primarily a limitation of the laboratory-scale demonstration turbine used for the present study. At around $250 \mathrm{~kW}_{\mathrm{e}}$ in size, the test facility was intended to be large enough to confront the fundamental issues for $\mathrm{sCO}_{2}$ Brayton cycle technology, but small enough to be affordable over several years of incremental funding. For adoption of $\mathrm{sCO}_{2}$ in a solar-thermal power plant, a number of required advances remain and are largely addressed by moving to larger equipment in $10 \mathrm{MW}_{\mathrm{e}}$ range. For large capacity factors and indirect systems, heat exchange between $\mathrm{CO}_{2}$ and a secondary fluid amenable to solar is also required. This represents a significant challenge in terms of material selection as well as heat exchanger design. Improvements in bearings and seals to prevent leakage are also required, especially as the system scales up from the small prototype included here.

\section{Acknowledgements}

This manuscript has been authored by Sandia National Laboratories, a multi-program laboratory managed and operated by Sandia Corporation, a wholly owned subsidiary of Lockheed Martin Corporation, for the U.S. Department of Energy's National Nuclear Security Administration under contract DE-AC04-94AL85000. The authors would also like to thank Craig Turchi for assistance with the economic analysis. 


\section{References}

[1] Hu, E., Yang, Y., Nishimura, A., Yilmaz, F., and Kouzani, A., 2010, "Solar thermal aided power generation," Applied Energy, Vol. 87, pp. 2881-2885.

[2] Denholm, P., Ela, E., Kirby, B., and Milligan, M., 2010, "The role of energy storage with renewable electricity generation," NREL/TP-6A2-47187, January 2010, National Renewable Energy Laboratory.

[3] Denholm, P. and Hand, M., 2011, "Grid flexibility and storage required to achieve very high penetration of variable renewable electricity," Energy Policy, Vol. 39, pp. 1817-1830.

[4] Sioshansi, R. and Denholm, P., 2010, "The value of concentrating solar power and thermal energy storage," NREL-TP-6A2-45833, February 2010, National Renewable Energy Laboratory.

[5] Kolb, G. J., Ho, C. K., Mancini, T. R., and Gary, J. A., 2011, "Power tower technology roadmap cost reduction plan," SAND2011-2419, April 2011, Sandia National Laboratories, Albuquerque, NM.

[6] U.S. Department of Energy, 2012, "SunShot Vision Study," accessed July 19, 2012 from http://www1.eere.energy.gov/solar/sunshot/vision_study.html.

[7] Sabharwall, P., Kim, E. S., and Patterson, M., 2011, "Fluoride high temperature reactor integration with industrial process applications," TEV-1160, March 29, 2011, Idaho National Laboratory, Idaho Falls, ID.

[8] Dostal, V., 2004, A supercritical carbon dioxide cycle for next generation nuclear reactors, PhD Thesis, Nuclear Engineering, Massachusetts Institute of Technology.

[9] Dostal, V., Hejzlar, P., and Driscoll, M. J., 2006, "The supercritical carbon dioxide power cycle: Comparison to other advanced power cycles," Nuclear Technology, Vol. 154, pp. 283-301.

[10] Chen, H., Goswami, D. Y., and Stefanakos, E. K., 2010, "A review of thermodynamic cycles and working fluids for the conversion of low-grade heat," Renewable and Sustainable Energy Reviews, Vol. 14, pp. 3059-3067.

[11] Utamura, M., Tamaura, Y., and Hasuike, H., 2007, "Some alternative technologies for solar thermal power generation," International Solar Energy Conference, July 8-13, 2006, Denver, CO, pp. 75-84.

[12] Ma, Z. and Turchi, C., 2011, "Advanced supercritical carbon dioxide power cycle configurations for use in concentrating solar power systems," NREL/CP-5500-50787, National Renewable Energy Laboratory, Golden, CO.

[13] Turchi, C. S., Ma, Z., Neises, T., and Wagner, 2012, "Thermodynamic study of advanced supercritical carbon dioxide power cycles for high performance concentrating solar power systems," Energy Sustainability, July 23-26, 2012, San Diego, CA.

[14] Conboy, T. M. and Wright, S. A., 2011, "Experimental investigations of the $\mathrm{s}-\mathrm{CO}_{2}$ condensing Brayton cycle," Supercritical $\mathrm{CO}_{2}$ Power Cycle Symposium, May 24-25, 2011, Arvada, CO.

[15] Conboy, T. M., Wright, S. A., Pasch, J., Fleming, D. D., and Rochau, G., 2011, "Initial splitflow test results and path forward," SAND2012-5308292, September 2011, Sandia National Laboratories, Albuquerque, NM.

[16] Wright, S. A., Conboy, T. M., Carlson, M. D., and Rochau, G., 2011, "High temperature split-flow re-compression Brayton cycle initial test results," SAND2012-5308349, July 2011, Sandia National Laboratories, Albuquerque, NM. 
[17] Wright, S. A., Fuller, R., Pickard, P. S., and Vernon, M. E., 2008, "Initial status and test results from a supercritical $\mathrm{CO}_{2}$ brayton cycle test loop," International Conference on Advances in Nuclear Power Plants, June 8-12, 2008, Anaheim, CA, pp. 768-775.

[18] Wright, S. A., Pickard, P. S., Fuller, R., Radel, R. F., and Vernon, M. E., 2009, "Supercritical $\mathrm{CO}_{2}$ Brayton cycle power generation development program and initial results," ASME Power Conference, July 21-23, 2009, Albuquerque, NM.

[19] Wright, S. A., Radel, R. F., Vernon, M. E., Rochau, G. E., and Pickard, P. S., 2010, "Operation and analysis of a supercritical $\mathrm{CO}_{2}$ Brayton Cycle," SAND2010-0171, Sandia National Laboratories, Albuquerque, NM.

[20] Wright, S. A., Conboy, T. M., Parma, E. J., Lewis, T. G., Rochau, G. A., and Suo-Anttila, A. J., 2011, "Summary of the Sandia supercritical $\mathrm{CO}_{2}$ development program," Supercritical $\mathrm{CO}_{2}$ Power Cycle Symposium, Boulder, CO.

[21] Wright, S. A., Fuller, R., Noall, J., Radel, R., Vernon, M. E., and Pickard, P. S., 2008, "Supercritical $\mathrm{CO}_{2}$ Brayton cycle compression and control near the critical point," International Conference on Advances in Nuclear Power Plants June 8-12, 2008, Anaheim, CA, pp. 810-819.

[22] Wright, S. A., Pickard, P. S., Vernon, M. E., Radel, R. F., and Fuller, R., 2009, "Description and test results from a supercritical $\mathrm{CO}_{2}$ Brayton cycle development program," 7th International Energy Conversion Engineering Conference, , August 2-5, 2009, Denver, CO.

[23] Wright, S. A., Vernon, M. E., Radel, R. F., and Fuller, R. L., 2009, "Supercritical $\mathrm{CO}_{2}$ main compressor performance measurements," American Nuclear Society Annual Meeting and Embedded Topical Meeting: Nuclear and Emerging Technologies for Space, June 14-18, 2009, Atlanta, GA, pp. 499-500.

[24] Moisseytsev, A. and Sienicki, J. J., 2005, "Control of supercritical $\mathrm{CO}_{2}$ brayton cycle for LFR autonomous load following," American Nuclear Society Winter Meeting, November 13-17, 2005, Washington D.C., pp. 342-344.

[25] Moisseytsev, A. and Sienicki, J. J., 2006, "Automatic control strategy development for the supercritical $\mathrm{CO}_{2}$ Brayton cycle for LFR autonomous load following," International Congress on Advances in Nuclear Power Plants, June 4-8, 2006, Reno, NV, pp. 732-741.

[26] Moisseytsev, A. and Sienicki, J. J., 2006, "Transient accident analysis of a supercritical carbon dioxide brayton cycle energy converter coupled to an autonomous lead-cooled fast reactor," 14th International Conference on Nuclear Engineering, ICONE 14, July 17-20, 2006, Miami, FL.

[27] Moisseytsev, A. and Sienicki, J. J., 2008, "Controllability of the supercritical carbon dioxide brayton cycle near the critical point," International Conference on Advances in Nuclear Power Plants, June 8-12, 2008, Anaheim, CA, pp. 799-809.

[28] Moisseytsev, A. and Sienicki, J. J., 2008, "Transient accident analysis of a supercritical carbon dioxide Brayton cycle energy converter coupled to an autonomous lead-cooled fast reactor," Nuclear Engineering and Design, Vol. 238, pp. 2094-2105.

[29] Vilim, R. B. and Moisseytsev, A., 2008, "Comparative analysis of supercritical $\mathrm{CO}_{2}$ power conversion system control schemes," International Conference on Advances in Nuclear Power Plants, June 8-12, 2008, Anaheim, CA, pp. 820-830.

[30] Dostal, V., Hejzlar, P., and Driscoll, M. J., 2006, "High-performance supercritical carbon dioxide cycle for next-generation nuclear reactors," Nuclear Technology, Vol. 154, pp. 265282.

[31] Dostal, V., Hejzlar, P., Todreas, N. E., and Buongiorno, J., 2004, "Medium-power lead-alloy fast reactor balance-of-plant options," Nuclear Technology, Vol. 147, pp. 388-405. 
[32] Moisseytsev, A. and Sienicki, J. J., 2009, "Investigation of alternative layouts for the supercritical carbon dioxide Brayton cycle for a sodium-cooled fast reactor," Nuclear Engineering and Design, Vol. 239, pp. 1362-1371.

[33] Sienicki, J. J., Moisseytsev, A., Cho, D. H., Momozaki, Y., Kilsdonk, D. J., Haglund, R. C., Reed, C. B., and Farmer, M. T., 2007, "Supercritical carbon dioxide Brayton cycle energy conversion for sodium-cooled fast reactors/advanced burner reactors," GLOBAL 2007: Advanced Nuclear Fuel Cycles and Systems, September 9-13, 2007, Boise, ID, pp. 12981307.

[34] Persichilli, M., Held, T., Hostler, S., Zdankiewicz, E., and Klapp, D., 2011, "Transforming waste heat to power through development of a $\mathrm{CO}_{2}$-based power cycle," Electric Power Expo, May 10-12, 2011, Rosemount, IL.

[35] Persichilli, M., Kacludis, A., Zdankiewicz, E., and Held, T., 2012, "Supercritical $\mathrm{CO}_{2}$ power cycle developments and commercialization: Why $\mathrm{SCO}_{2}$ can displace steam," Power-Gen India and Central Asia, April 19-21, 2012, Pragati Maidan, New Delhi, India.

[36] Chacartegui, R., Muñoz de Escalona, J. M., Sánchez, D., Monje, B., and Sánchez, T., 2011, "Alternative cycles based on carbon dioxide for central receiver solar power plants," Applied Thermal Engineering, Vol. 31, pp. 872-879.

[37] Southwest Research Institute, Department of Energy, Sunshot Initiative, 2012, "Supercritical carbon dioxide turbo-expander and heat exchangers," accessed May 30, 2013 from http://www1.eere.energy.gov/solar/sunshot/csp_sunshotrnd_swri_exchangers.html.

[38] Angelino, G., 1968, "Carbon dioxide condensation cycles for power production," Journal of Engineering for Power, Vol. 90, pp. 287-296.

[39] Pasch, J., Conboy, T. M., Fleming, D. D., and Rochau, G., 2012, "Supercritical $\mathrm{CO}_{2}$ recompression Brayton cycle: completed assembly description," SAND2012-9546, October 2012, Sandia National Laboratories, Albuquerque, NM.

[40] Wright, S. A., Conboy, T. M., and Rochau, G., 2011, "Break-even power transients for two simple recuperated $\mathrm{S}-\mathrm{CO}_{2}$ Brayton cycle test configurations," S-CO2 Power Cycle Symposium, May 24-24, 2011, Boulder, CO.

[41] Bruckner, R. J., 2009, "Windage power loss in gas foil bearings and the rotor-stator clearance of high speed generators operating in high pressure environments," NASA/TM2009-215826 November 2009, NASA, Glenn Research Center, Cleveland, OH.

[42] Conboy, T. M., 2012, "Gas bearings and seals development for supercritical $\mathrm{CO}_{2}$ turbomachinery," SAND2012-8895, Sandia National Laboratories, Albuquerque, NM.

[43] Schlichting, H. and Gersten, K., 2000, Boundary-Layer Theory, 8th ed. New York, Springer.

[44] Vrancik, J. E., 1968, "Prediction of windage power loss in alternators," NASA TN D-4849, October 1968, NASA Technical Note, Lewis Research Center, Cleveland, OH.

[45] Lemmon, E. W., Huber, M. L., and McLinden, M. O., 2010, "NIST reference fluid thermodynamic and transport properties - REFPROP v9.0," User's Guide, NIST Standard Reference Database 23, 2010.

[46] Angelino, G., 1969, "Real gas effects in carbon dioxide cycles," ASME International Gas Turbine Conference and Products Show GT-102, March 10-13, 1969, Cleveland, OH.

[47] Sienicki, J. J., Moisseytsev, A., Fuller, R. L., Wright, S. A., and Pickard, P. S., 2011, "Scale dependencies of supercritical carbon dioxide Brayton cycle technologies and the optimal size for a next-step supercritical $\mathrm{CO}_{2}$ cycle demonstration," $\mathrm{SCO}_{2}$ Power Cycle Symposium, May 24-25, 2011, Boulder, CO.

[48] Kelly, B., 2010, "Advanced thermal storage for central receivers with supercritical coolants," Grant DE-FG36-08G018149, Abengoa Solar. 
[49] Clark, D. E. and Mizia, R. E., 2012, "Diffusion welding of alloys for molten salt service status report," INL/EXT-12-24589, May 2012, Idaho National Laboratory, Idaho Falls, ID.

[50] Heatric, "Heat Exchangers," accessed February 6, 2012 from http://www.heatric.com/.

[51] Sabharwall, P., Kim, E. S., McKellar, M., Anderson, N., and Patterson, M., 2011, "Process heat exchanger options for the advanced high temperature reactor," INL/EXT-11-21584, June 2011, Idaho National Laboratory, Idaho Falls, ID.

[52] Sabharwall, P., Kim, E. S., Siahpush, A., Anderson, N., Glazoff, M., Phoenix, B., Mizia, R., Clark, D., McKellar, M., and Patterson, M., 2011, "Feasibility study of secondary heat exchanger concepts for the advanced high temperature reactor," INL/EXT-11-23076, September 2011, Idaho National Laboratory, Idaho Falls, ID.

[53] Reed, C. B., Momozaki, Y., Chojnowski, D. B., and Sienicki, J. J., 2011, "Progress report on small-scale experiment designs for the investigation of fundamental phenomena in compact sodium heat exchangers," ANL-ARC-210, September 30, 2011, Argonne National Laboratory.

[54] Momozaki, Y., Cho, D. H., Sienicki, J. J., and Moisseytsev, A., 2010, "Experimental investigations on sodium plugging in narrow flow channels," Nuclear Technology, Vol. 171, pp. 153-160.

[55] Sienicki, J., Moisseytsev, A., Cho, D., Thomas, M., Vilim, R., Momozaki, Y., Lomperski, S., and Farmer, M., 2009, "Recent research and development on the supercritical carbon dioxide Brayton cycle at Argonne National Laboratory - Presentation," Supercritical $\mathrm{CO}_{2}$ Power Cycle Symposium, Rensselaer Polytechnic Institute, Troy, NY.

[56] Janz, G. J., Allen, C. B., Downey, J. R., and Tomkins, R. P. T., 1978, "Physical properties data compilations relevant to energy storage. I. Molten salts: eutectic data," NSRDS-NBS 61-I, National Standard Reference Data System, National Bureau of Standards.

[57] Rochau, G., "Estimated percentage cost of heat exchangers for $\mathrm{sCO}_{2}$ Brayton power cycle," Personal Communication ed, 2012.

[58] Carlson, M. D., Kruizenga, A., Anderson, M. H., and Corradini, M., 2011, "Measurements of heat transfer and pressure drop characteristics of supercritical carbon dioxide flowing in zig-zag printed circuit heat exchanger channels," Supercritical $\mathrm{CO}_{2}$ Power Cycle Symposium, May 24-25, 2011, Boulder, CO.

[59] Carlson, M. D., Kruizenga, A. M., Anderson, M. H., and Corradini, M. L., 2012, "Heat transfer and pressure drop of supercritical carbon dioxide flowing in several printed circuit heat exchanger channel patterns," International Congress on Advances in Nuclear Power Plants, June 24-28, 2012, Chicago, IL.

[60] Fatima, R., Kruizenga, A., Anderson, M., and Ranjan, D., 2011, "Numerical investigation of thermal hydraulic behavior of supercritical carbon dioxide in compact heat exchangers " Supercritical $\mathrm{CO}_{2}$ Power Cycle Symposium, May 24-25, 2011, Boulder, CO.

[61] Ishizuka, T., Kato, Y., Muto, Y., Nikitin, K., and Tri Lam, N., 2006, "Thermal-hydraulic characteristics of a printed circuit heat exchanger in a supercritical $\mathrm{CO}_{2}$ loop," Bulletin of the Research Laboratory for Nuclear Reactors, Vol. 30, pp. 109-16.

[62] Kim, D. E., Kim, M. H., Cha, J. E., and Kim, S. O., 2008, "Numerical investigation on thermal-hydraulic performance of new printed circuit heat exchanger model," Nuclear Engineering and Design, Vol. 238, pp. 3269-3276.

[63] Kim, I. H., No, H. C., Lee, J. I., and Jeon, B. G., 2009, "Thermal hydraulic performance analysis of the printed circuit heat exchanger using a helium test facility and CFD simulations," Nuclear Engineering and Design, Vol. 239, pp. 2399-2408.

[64] Kruizenga, A. M., Anderson, M., and Corradini, M., 2009, "Mini-channel supercritical $\mathrm{CO}_{2}$ heat transfer measurements for Brayton cycle regenerators," 17th International 
Conference on Nuclear Engineering, ICONE17 July 12-16, 2009, Brussels, Belgium, pp. 787792.

[65] Kruizenga, A. M., Anderson, M., Fatima, R., Corradini, M., Towne, A., and Ranjan, D., 2011, "Heat transfer of supercritical carbon dioxide in printed circuit heat exchanger geometries," Journal of Thermal Science and Engineering Applications, Vol. 3.

[66] Li, H., Kruizenga, A., Anderson, M., Corradini, M., Luo, Y., Wang, H., and Li, H., 2011, "Development of a new forced convection heat transfer correlation for $\mathrm{CO}_{2}$ in both heating and cooling modes at supercritical pressures," International Journal of Thermal Sciences, Vol. 50, pp. 2430-2442.

[67] Ngo, T. L., Kato, Y., Nikitin, K., and Ishizuka, T., 2007, "Heat transfer and pressure drop correlations of microchannel heat exchangers with S-shaped and zigzag fins for carbon dioxide cycles," Experimental Thermal and Fluid Science, Vol. 32, pp. 560-570.

[68] Ngo, T. L., Kato, Y., Nikitin, K., and Tsuzuki, N., 2006, "New printed circuit heat exchanger with S-shaped fins for hot water supplier," Experimental Thermal and Fluid Science, Vol. 30, pp. 811-819.

[69] Nikitin, K., Kato, Y., and Ngo, L., 2006, "Printed circuit heat exchanger thermal-hydraulic performance in supercritical $\mathrm{CO}_{2}$ experimental loop," International Journal of Refrigeration, Vol. 29, pp. 807-14.

[70] Tsuzuki, N., Kato, Y., and Ishisuka, T., 2007, "High performance printed circuit heat exchanger," Applied Thermal Engineering, Vol. 27, pp. 1702-7.

[71] Tsuzuki, N., Kato, Y., Nikitin, K., and Ishizuka, T., 2009, "Advanced microchannel heat exchanger with S-shaped fins," Journal of Nuclear Science and Technology, Vol. 46, pp. 403-412.

[72] Abramov, A. V., Polovov, I. B., Volkovich, V. A., Rebrin, O. I., Griffiths, T. R., May, I., and Kinoshita, H., 2010, "Spectroelectrochemical study of stainless steel corrosion in $\mathrm{NaCl}-\mathrm{KCl}$ melt," 17th International Symposium on Molten Salts and lonic Liquids - 218th ECS Meeting, October 10-15, 2010, Las Vegas, NV, pp. 277-285.

[73] Bradshaw, R. W., 1980, "Corrosion of 304SS by molten $\mathrm{NaNO}_{3}-\mathrm{KNO}_{3}$ in a thermal convection loop," SAND80-8856, Sandia National Laboratories, pp. 40.

[74] Bradshaw, R. W. and Goods, S. H., 2001, "Accelerated corrosion testing of a nickel-base alloy in a molten salt," SAND2001-8758, Sandia National Laboratories, Albuquerque, NM.

[75] Susskind, H., Hill, F. B., Green, L., Kalish, S., Kukacka, L. E., McNulty, W. E., and Wirsing, E., 1960, "Corrosion studies for a fused salt-liquid metal extraction process for the liquid metal fuel reactor," BNL 585, Brookhaven National Laboratory.

[76] Williams, D. F., Wilson, D. F., Toth, L. M., Caja, J., and Keiser, J. R., 2003, "Research on molten fluorides as high temperature heat transfer agents," GLOBAL 2003, November 20, 2003, New Orleans, Louisiana.

[77] Indacochea, J. E., Smith, J. L., Litko, K. R., and Karell, E. J., 1999, "Corrosion performance of ferrous and refractory metals in molten salts under reducing conditions," Journal of Materials Research, Vol. 14, pp. 1990-1995.

[78] Cao, G., Firouzdor, V., Sridharan, K., Anderson, M., and Allen, T. R., 2012, "Corrosion of austenitic alloys in high temperature supercritical carbon dioxide," Corrosion Science, Vol. 60, pp. 246-255.

[79] Moore, R. and Conboy, T. M., 2012, "Metal corrosion in a supercritical $\mathrm{CO}_{2} /$ liquid sodium power cycle," SAND2012-0184, Sandia National Laboratories, Albuquerque, NM.

[80] Gomez, J. C., 2012, "Degradation mechanisms and development of protective coatings for TES and HTF containment materials," SunShot Lab Proposal Development Process, National Renewable Energy Laboratory. 
[81] 2012, Personal communication with Robert Bruckner and Chris DellaCorte, NASA Glenn Research Center.

[82] Moore, R. C. and Conboy, T. M., 2012, "Metal corrosion in a supercritical carbon dioxide liquid sodium power cycle," SAND2012-0184, Sandia National Laboratories, Albuquerque, NM.

[83] Bradshaw, R. W., 1987, "Oxidation and chromium depletion of alloy 800 and 316 SS by molten $\mathrm{NaNO}_{3}-\mathrm{KNO}_{3}$ at temperatures above 600 degrees centigrade," SAND86-9009, Sandia National Laboratories, Livermore CA.

[84] Frangini, S., 2008, "Corrosion of metallic stack components in molten carbonates: critical issues and recent findings," Journal of Power Sources, Vol. 182, pp. 462-468.

[85] Grabke, H. J., Reese, E., and Spiegel, M., 1995, "The effects of chlorides, hydrogen chloride, and sulfur dioxide in the oxidation of steels below deposits," Corrosion Science, Vol. 37, pp. 1023-1043.

[86] Goods, S. H., Bradshaw, R. W., Clift, M. J., and Boehme, D. R., 1997, "The effect of silicon on the corrosion characteristics of 2-1/4Cr-1Mo Steel in molten nitrate salt," SAND978269, Sandia National Laboratories, Livermore, CA.

[87] Zeng, C. L. and Liu, Y., 2011, "A comparative study of the corrosion behavior of three stainless steels in an eutectic $(\mathrm{Li}, \mathrm{Na}, \mathrm{K})_{2} \mathrm{CO}_{3}$ melt with and without $(\mathrm{Na}, \mathrm{K}) \mathrm{Cl}$ additives at 973 $\mathrm{K}$ in air," High Temperature Materials and Processes, Vol. 30, pp. 161-169.

[88] Nishikata, A., Numata, H., and Tsuru, T., 1991, "Electrochemistry of molten salt corrosion," Materials Science and Engineering A, Vol. A146, pp. 15-31.

[89] Littlewood, R. and Argent, E. J., 1961, "Electrochemical studies of the behaviour of metals in fused chlorides," Electrochimica Acta, Vol. 4, pp. 155-169.

[90] Williams, D. F., 2006, "Assessment of candidate molten salt coolants for the NGNP/NHI heat-transfer loop," ORNL/TM-2006/69, Oak Ridge National Laboratory.

[91] Williams, D. F., Toth, L. M., and Clarno, K. T., 2006, "Assessment of candidate molten salt coolants for the advanced high-temperature reactor (AHTR)," ORNL/TM-2006/12, Oak Ridge National Laboratories.

[92] Olson, L., 2009, Materials corrosion in molten LiF-NaF-KF eutectic salt, Doctor of Philosophy Thesis, Nuclear Engineering, University of Wisconsin-Madison, Madison, Wisconsin.

[93] Ambrosek, J., 2011, Molten chloride salts for heat transfer in nuclear systems, Doctor of Philosophy Thesis, Nuclear Engineering and Engineering Physics, University of WisconsinMadison, Madison, WI.

[94] DeVan, J. H. and Evans, R. B., 1962, "Corrosion behavior of reactor materials in fluoride salt mixtures," ORNL-TM-328, Oak Ridge National Laboratory, Oak Ridge, TN.

[95] Coyle, R. T., Thomas, T. M., and Lai, G. Y., 1986, "Exploratory corrosion tests on alloys in molten salts at 900 degrees $C$," Journal of materials for energy systems, Vol. 7, pp. 345352.

[96] Kruizenga, A., 2012, "Corrosion mechanisms in chloride and carbonate salts," SAN20127594, September 2012, Sandia National Laboratories, Livermore CA.

[97] Indacochea, J. E., Smith, J. L., Litko, K. R., Karell, E. J., and Raraz, A. G., 2001, "Hightemperature oxidation and corrosion of structural materials in molten chlorides," Oxidation of Metals, Vol. 55, pp. 1-16.

[98] Li, X., Le Pierres, R., and Dewson, S. J., 2006, "Heat exchangers for the next generation of nuclear reactors," International Congress on Advances in Nuclear Power Plants, ICAPP, June 4-8, 2006, Reno, NV, United states, pp. 201-209. 
[99] Li, X., Kininmont, D., Le Pierces, R., and Dewson, S. J., 2008, "Alloy 617 for the high temperature diffusion-bonded compact heat exchangers," International Conference on Advances in Nuclear Power Plants, ICAPP, June 8-12, 2008, Anaheim, CA, pp. 282-288.

[100] Haynes International, 2007, "Haynes 230 Alloy." 
Table 1. Nominal performance values corresponding to Brayton cycle components shown in Figure 1.

\begin{tabular}{|c|c|}
\hline Parameter & Design Point Values \\
\hline Heater input & $780[\mathrm{~kW}]$ \\
\hline Pre-cooler & $531[\mathrm{~kW}]$ \\
\hline Turbine A efficiency & $87 \%$ \\
\hline Turbine B efficiency & $87 \%$ \\
\hline Main compressor efficiency & $68 \%$ \\
\hline Recompressor efficiency & $68 \%$ \\
\hline Alternator rated power & $123[\mathrm{~kW}]$ \\
\hline LT recuperator & $610[\mathrm{~kW}]$ \\
\hline HT recuperator & $2232[\mathrm{~kW}]$ \\
\hline
\end{tabular}


Table 2. State points and operational parameters measured at steady operation. Calculated columns include (a) model benchmarking, (b) cycle operation at design conditions, (c) insulation improvements to reduce heat loss, and (d) compressor design improvements to reach $80 \%$ efficiency.

\begin{tabular}{|c|c|c|c|c|c|}
\hline Location & $\begin{array}{c}\text { Measured } \\
\text { (Figure 4, } \\
7600 \text { s) }\end{array}$ & $\begin{array}{c}\text { Calculated } \\
\text { (a) } \\
\text { benchmark }\end{array}$ & $\begin{array}{c}\text { Calculated } \\
\text { (b) } \\
\text { design } \\
\text { conditions }\end{array}$ & $\begin{array}{c}\text { Calculated } \\
\text { (c) } \\
\text { insulated }\end{array}$ & $\begin{array}{c}\text { Calculated } \\
\text { (d) } \\
\text { efficient } \\
\text { compressor }\end{array}$ \\
\hline \multicolumn{6}{|c|}{ Temperature $\left[{ }^{\circ} \mathrm{C}\right]$} \\
\hline 1a-A & 32.3 & 31.9 & 32.4 & 32.4 & 32.4 \\
\hline $1 b-A^{d}$ & 31.8 & 31.9 & 32.4 & 32.4 & 32.4 \\
\hline $2 a-A$ & 46.8 & 47.6 & 52.6 & 52.5 & 51.6 \\
\hline $2 b-A$ & 45.7 & 47.6 & 52.6 & 52.5 & 51.6 \\
\hline $3 a-A$ & 55.8 & 52.7 & 119.6 & 120.8 & 116.3 \\
\hline $3 a-B$ & 69.5 & 71 & 115.5 & 116.4 & 110.2 \\
\hline $3 b$ & 58.7 & 55.8 & 117.7 & 118.8 & 113.5 \\
\hline $4 a$ & 331.7 & 316.7 & 422.7 & 435 & 432.9 \\
\hline $4 b$ & 316.1 & 301.1 & 407.1 & 435 & 432.9 \\
\hline $5 a$ & 400.4 & 400.4 & 538 & 538 & 538 \\
\hline $5 b-A$ & 390 & 394.1 & 531.7 & 538 & 538 \\
\hline $5 b-B$ & 390.6 & 394.6 & 532.2 & 538 & 538 \\
\hline $6 a-A$ & 368.9 & 368.5 & 473.7 & 484.6 & 484.5 \\
\hline $6 a-B$ & 368.9 & 367.7 & 473.8 & 484.1 & 484 \\
\hline $6 b$ & 366.3 & 365.5 & 471.1 & 484.3 & 484.2 \\
\hline $7 a$ & 67 & 61 & 135.8 & 137.8 & 132.2 \\
\hline $7 b$ & 67 & 61 & 135.8 & 137.8 & 132.2 \\
\hline $8 a$ & 45.9 & 47.7 & 64.3 & 64.2 & 63 \\
\hline $8 b-A$ & 44.6 & 47.7 & 64.3 & 64.2 & 63 \\
\hline $8 b-B$ & 45.1 & 46.9 & 63.5 & 64.2 & 63 \\
\hline \multicolumn{6}{|c|}{ Pressure [kPa] } \\
\hline $1 a-A$ & 7530.7 & 7485 & 7688 & 7688 & 7688 \\
\hline $1 b-A^{d}$ & 7485.1 & 7485 & 7688 & 7688 & 7688 \\
\hline $2 a-A$ & 10296.9 & 10218.6 & 14091.3 & 14078.3 & 14099.7 \\
\hline $2 b-A$ & 10156.8 & 10218.6 & 14091.3 & 14078.3 & 14099.7 \\
\hline $3 a-A$ & 10067.4 & 10136.8 & 13978.5 & 13965.6 & 13986.9 \\
\hline $3 a-B$ & 10020.4 & 10126.1 & 13963.1 & 13967.1 & 13980.2 \\
\hline $3 b$ & 10017.3 & 10126.1 & 13963.1 & 13967.1 & 13980.2 \\
\hline $4 a$ & 10117.1 & 10045.1 & 13851.4 & 13855.4 & 13868.3 \\
\hline $4 b$ & 10045.3 & 10045.1 & 13851.4 & 13855.4 & 13868.3 \\
\hline $5 a^{d}$ & 9898.5 & 9797.8 & 13472.3 & 13477.4 & 13489.7 \\
\hline $5 b-A$ & 9893.7 & 9797.8 & 13472.3 & 13477.4 & 13489.7 \\
\hline $5 b-B$ & 9852.6 & 9797.8 & 13472.3 & 13477.4 & 13489.7 \\
\hline
\end{tabular}




\begin{tabular}{|c|c|c|c|c|c|}
\hline $6 a-A$ & 7938.4 & 7933.7 & 8416.4 & 8413.6 & 8415.3 \\
\hline $6 a-B$ & 7962.5 & 7933.7 & 8416.4 & 8413.6 & 8415.3 \\
\hline $6 b$ & 7983.2 & 7933.7 & 8416.4 & 8413.6 & 8415.3 \\
\hline $7 a$ & 7844.5 & 7808.8 & 8283.8 & 8281.1 & 8282.7 \\
\hline $7 b$ & 7922.2 & 7808.8 & 8283.8 & 8281.1 & 8282.7 \\
\hline $8 a$ & 7783 & 7685.8 & 8153.4 & 8150.7 & 8152.3 \\
\hline $8 b-A$ & 7553.1 & 7685.8 & 8153.4 & 8150.7 & 8152.3 \\
\hline $8 b-B$ & 7573.5 & 7685.8 & 8153.4 & 8150.7 & 8152.3 \\
\hline \multicolumn{6}{|c|}{ Mass flow $[\mathrm{kg} / \mathrm{s}]$} \\
\hline $2 a-A$ & 2.506 & 2.767 & 3.098 & 3.134 & 3.071 \\
\hline $3 a-B$ & 0.977 & 0.888 & 2.534 & 2.481 & 2.554 \\
\hline $4 b$ & 3.483 & 3.655 & 5.632 & 5.615 & 5.625 \\
\hline $5 b-A$ & 1.741 & 1.803 & 2.626 & 2.619 & 2.623 \\
\hline $5 b-B$ & 1.741 & 1.854 & 3.007 & 2.996 & 3.001 \\
\hline $6 a-A$ & 1.712 & 1.774 & 2.597 & 2.589 & 2.593 \\
\hline $6 a-B$ & 1.716 & 1.829 & 2.982 & 2.972 & 2.977 \\
\hline $8 b-A$ & 2.535 & 2.797 & 3.127 & 3.164 & 3.101 \\
\hline $8 b-B$ & 1.002 & 0.912 & 2.559 & 2.506 & 2.578 \\
\hline \multicolumn{6}{|c|}{ TAC A } \\
\hline $\mathrm{RPM}^{\mathrm{d}}$ & 36550 & 36550 & 75000 & 75000 & 75000 \\
\hline Windage $^{a}[\mathrm{~kW}]$ & $N / A^{e}$ & 4.9 & 25.8 & 25.8 & 25.8 \\
\hline Turbine heat loss ${ }^{\mathrm{b}}[\mathrm{kW}]$ & 8.1 & 10.5 & 16.0 & 0.0 & 0.0 \\
\hline Turbine power (gross) [kW] & 36.4 & 36.9 & 151.8 & 153.7 & 154.2 \\
\hline Turbine efficiency [\%] & 79.1 & 80.8 & 84.6 & 84.6 & 84.6 \\
\hline Compressor pressure ratio & 1.376 & 1.365 & 1.833 & 1.831 & 1.834 \\
\hline Compressor power [kW] & 39.2 & 25.5 & 47.5 & 47.9 & 36.4 \\
\hline Compressor efficiency [\%] & 36.3 & 67.8 & 67.1 & 67.3 & 87.1 \\
\hline TAC A net power [kW] & 10.9 & 6.5 & 78.5 & 80.0 & 92.0 \\
\hline \multicolumn{6}{|c|}{ TAC B } \\
\hline $\mathrm{RPM}^{\mathrm{d}}$ & 46025 & 46025 & 75000 & 75000 & 75000 \\
\hline Windage $^{a}[\mathrm{~kW}]$ & $N / A^{e}$ & 10.1 & 25.8 & 25.8 & 25.8 \\
\hline Turbine heat loss ${ }^{\mathrm{b}}[\mathrm{kW}]$ & 8.1 & 10.8 & 18.3 & 0.0 & 0.0 \\
\hline Turbine power (gross) [kW] & 37.8 & 40.8 & 176.0 & 178.0 & 178.6 \\
\hline Turbine efficiency [\%] & 84.6 & 86.5 & 85.4 & 85.3 & 85.3 \\
\hline Compressor pressure ratio & 1.323 & 1.318 & 1.713 & 1.714 & 1.715 \\
\hline Compressor power [kW] & 16.7 & 14.9 & 93.2 & 91.6 & 72.2 \\
\hline Compressor efficiency [\%] & 61.9 & 63.4 & 68.3 & 68.7 & 88.6 \\
\hline TAC B net power [kW] & 5.7 & 15.8 & 57.0 & 60.6 & 80.6 \\
\hline \multicolumn{6}{|c|}{ System Parameters } \\
\hline Heater input $[\mathrm{kW}]$ & 341.7 & 422.6 & 891.0 & 700.9 & 716.5 \\
\hline Pre-cooler [kW] & 239.2 & 240.2 & 476.4 & 481.3 & 464.8 \\
\hline
\end{tabular}




\begin{tabular}{|c|c|c|c|c|c|}
\hline LT recuperator UA [kW/K] & 67.6 & 67.6 & 70.0 & 70.0 & 70.0 \\
\hline HT recuperator UA [kW/K] & 55.2 & 55.2 & 40.0 & 40.0 & 40.0 \\
\hline Mass loading [kg] & 101.2 & 101.8 & 104.0 & 103.3 & 104.2 \\
\hline Heat loss $^{c} 4$ a to 4b [kW] & 62.3 & 65.8 & 104.9 & 0.0 & 0.0 \\
\hline Heat loss $^{c}$ 5a to 5b [kW] & 40.9 & 25.8 & 41.5 & 0.0 & 0.0 \\
\hline Heat loss $^{c}$ 6a to 6b [kW] & 10.5 & 10.8 & 17.2 & 0.1 & 0.1 \\
\hline Net electricity [kW] & 16.6 & 22.3 & 135.5 & 140.6 & 172.6 \\
\hline Cycle efficiency [\%] & 4.9 & 5.3 & 15.2 & 20.0 & 24.1 \\
\hline
\end{tabular}

${ }^{a}$ Obtained using data presented in Figure 6

bobtained following section 3

${ }^{\mathrm{C}}$ Obtained following the approach in section 2.3.1

dInput parameter for model

${ }^{\mathrm{e}}$ Not directly measured 


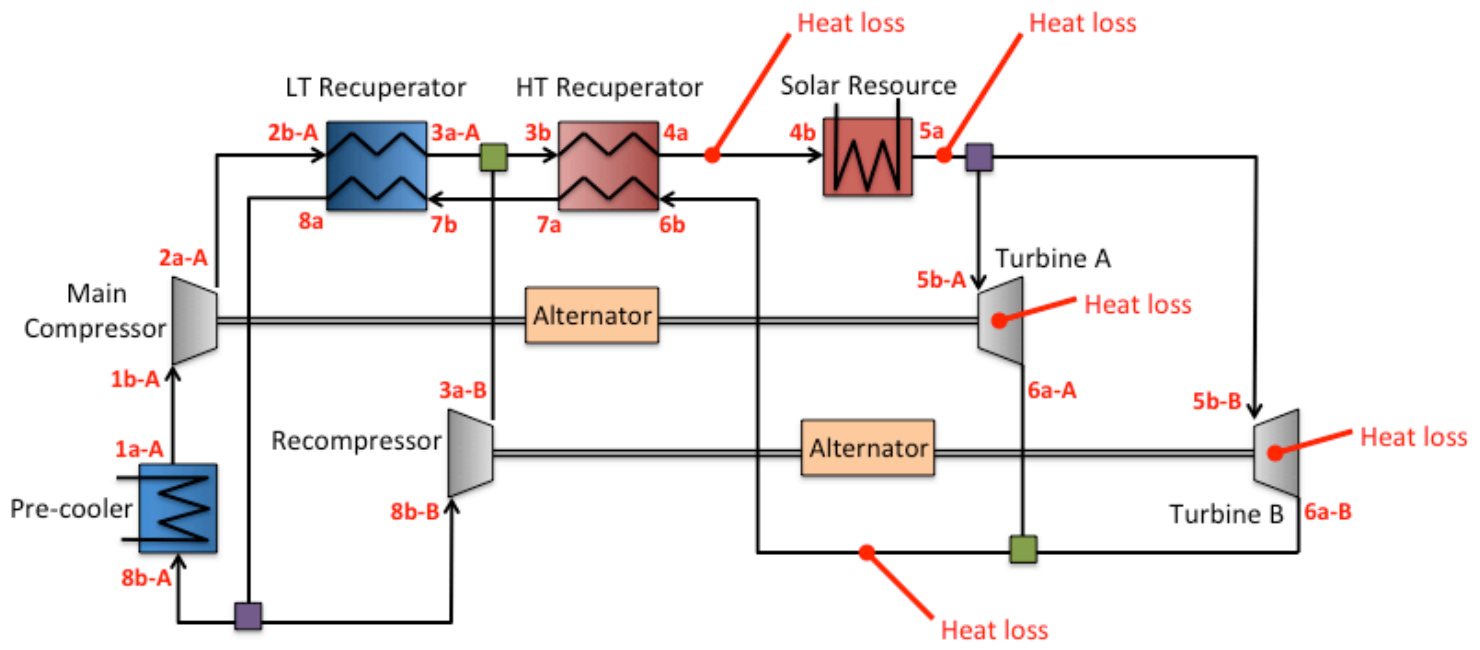

Figure 1. Layout of split-flow recompression Brayton cycle components. 


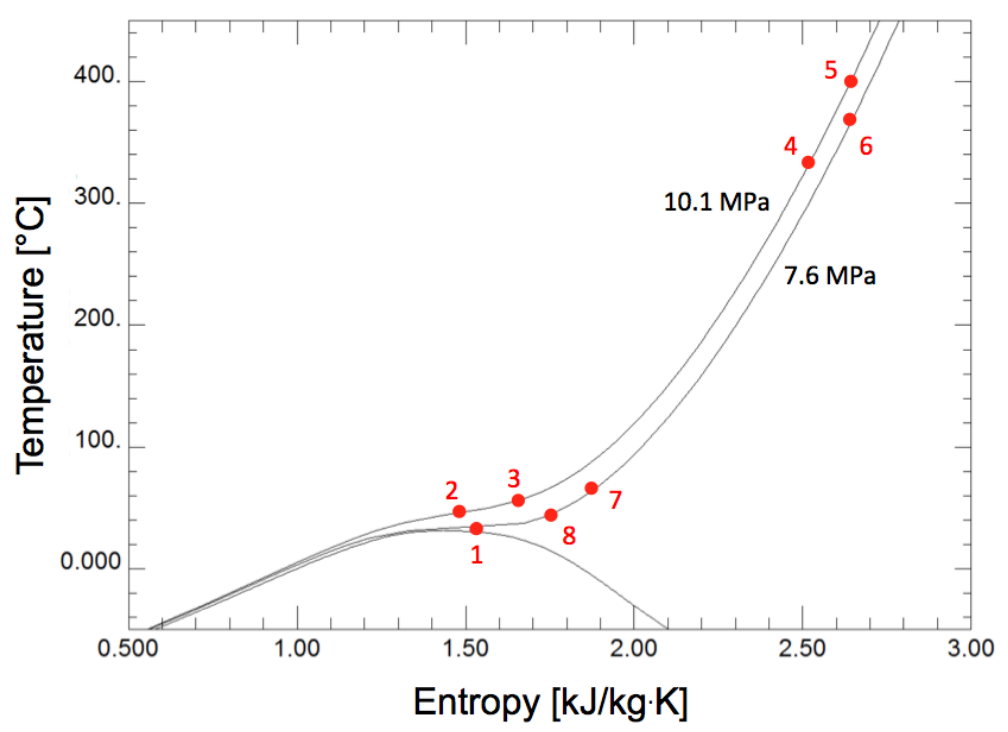

(a)

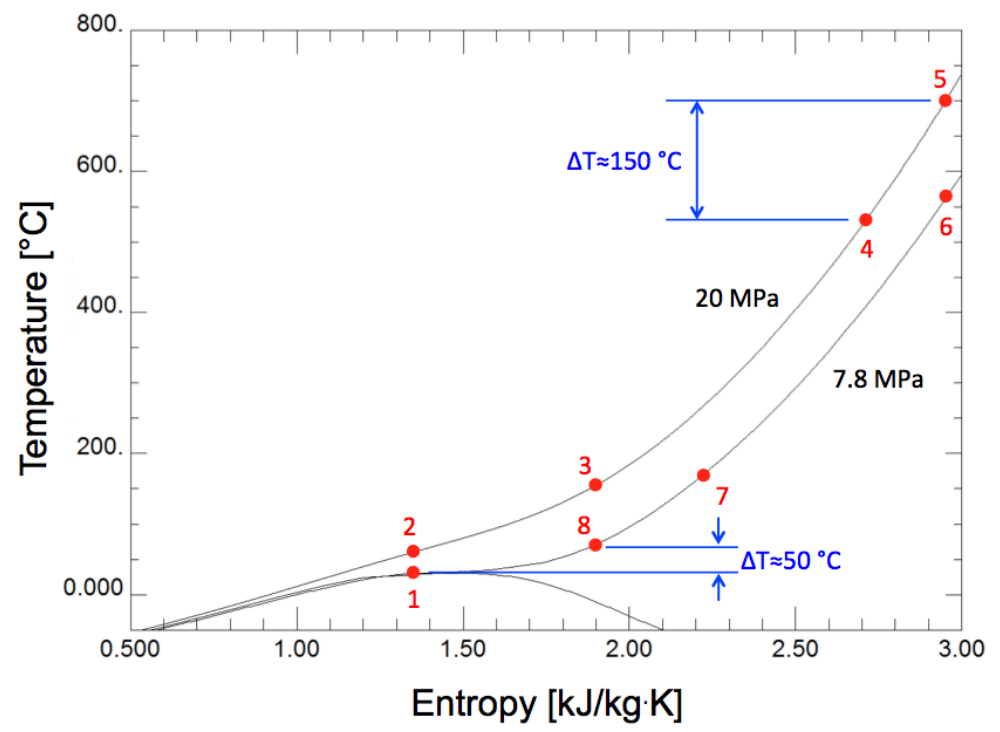

(b)

Figure 2. (a) Typical current system operating conditions at Sandia National Laboratories and (b) projected system operation by Dostal et al. [30]. 


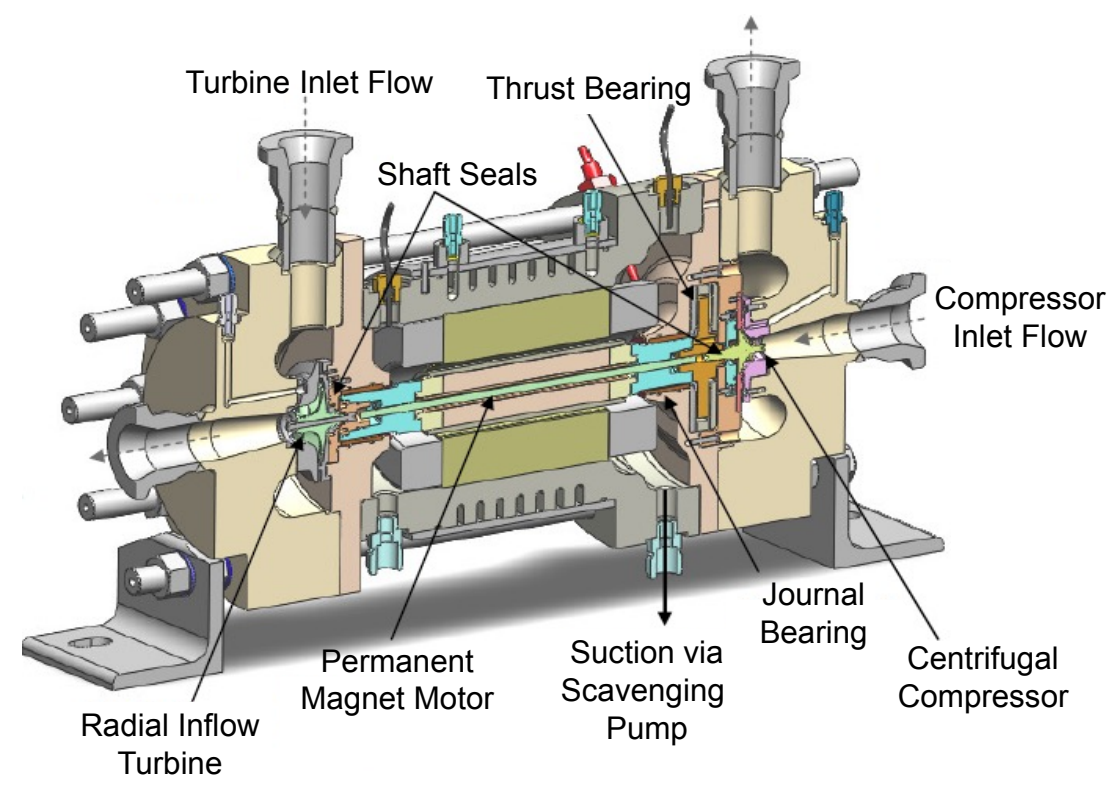

Figure 3. Schematic of the internals for the Sandia $\mathrm{sCO}_{2}$ Turbo-alternator-compressor. 


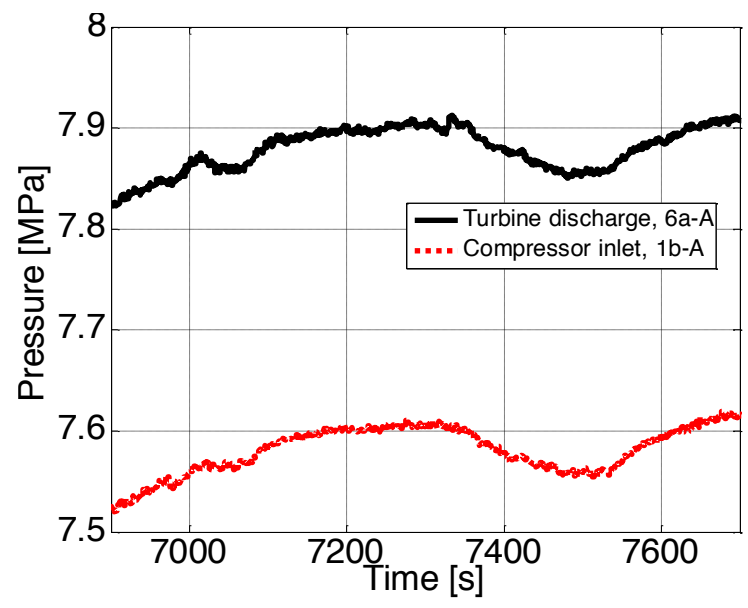

a)

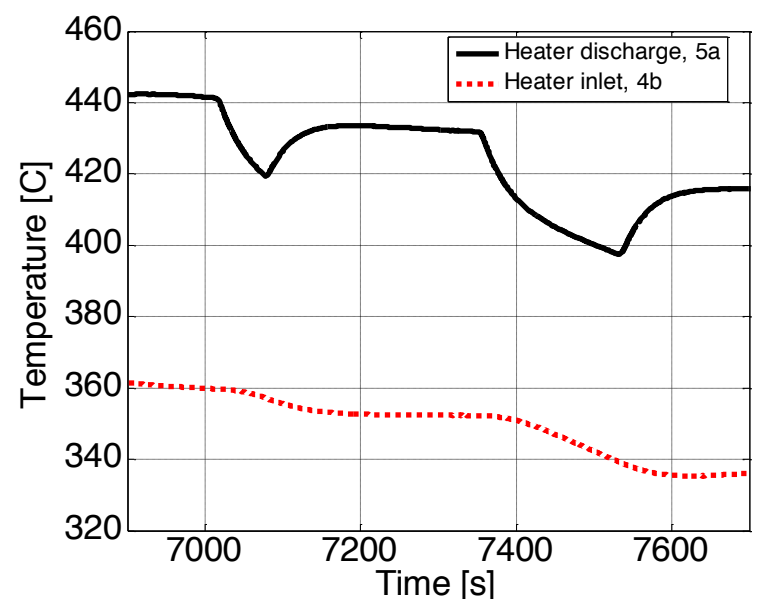

(c)

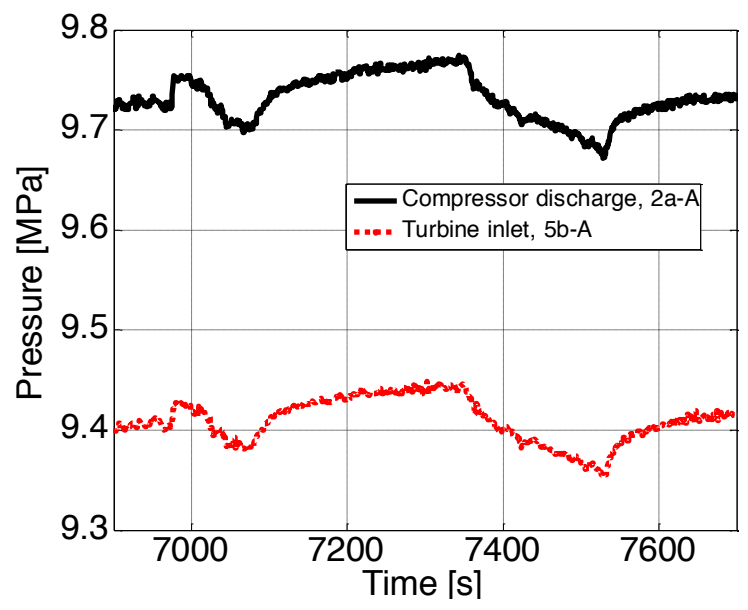

(b)

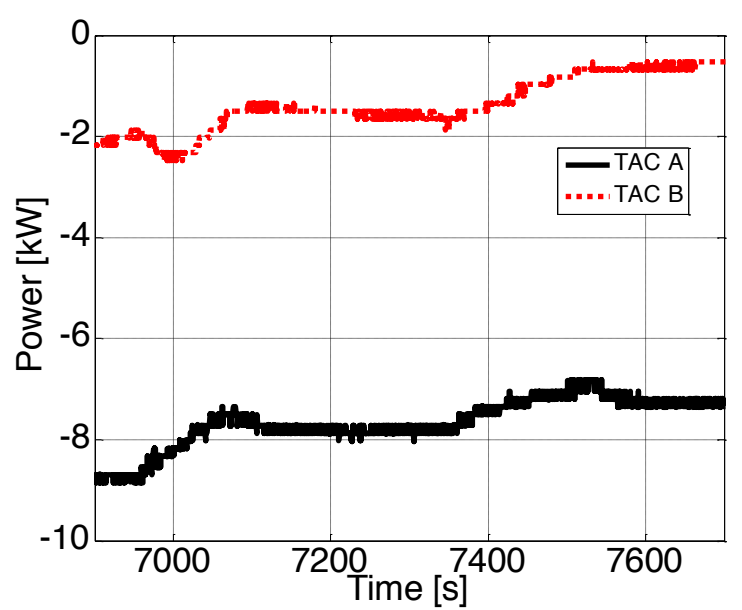

(d)

Figure 4. System response to 50\% reduction in power setting lasting approximately one minute and two and a half minutes. (a) Low pressure response, (b) high pressure response, (c) transient source boundary temperatures, and (d) system net power generation response (negative power indicates power production from the system). 


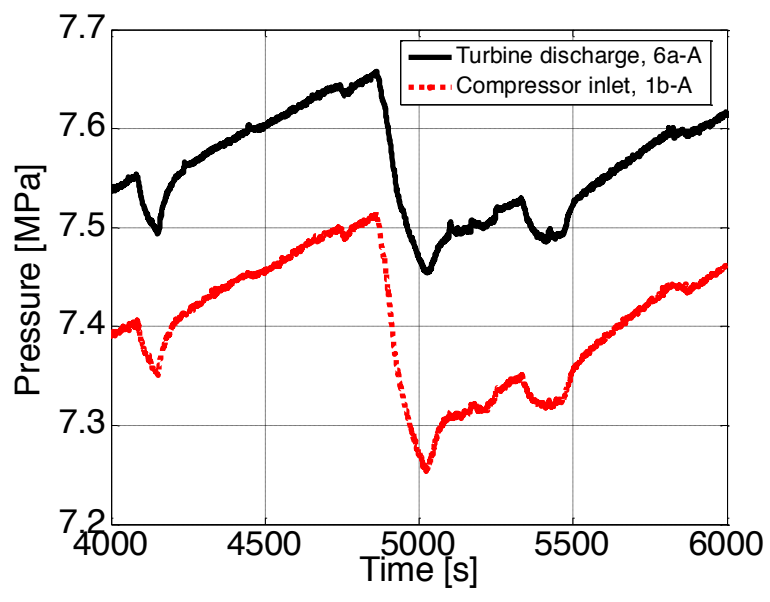

(a)

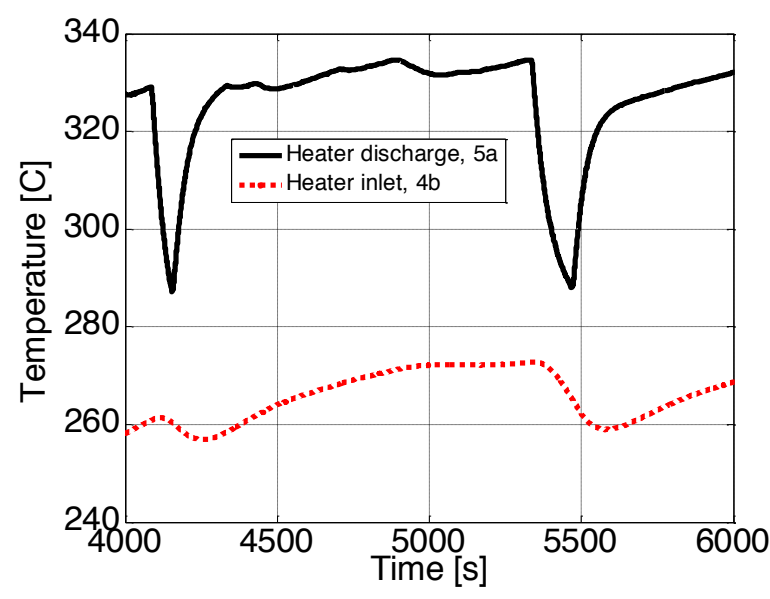

(c)

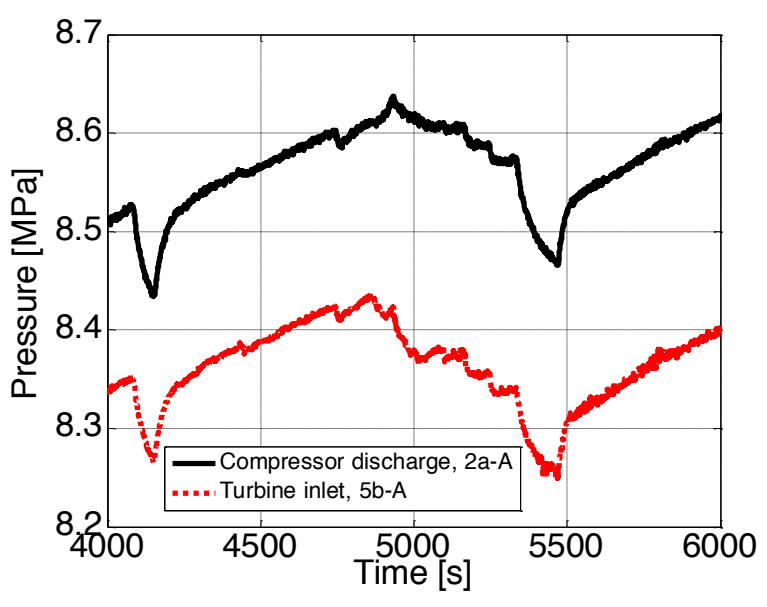

(b)

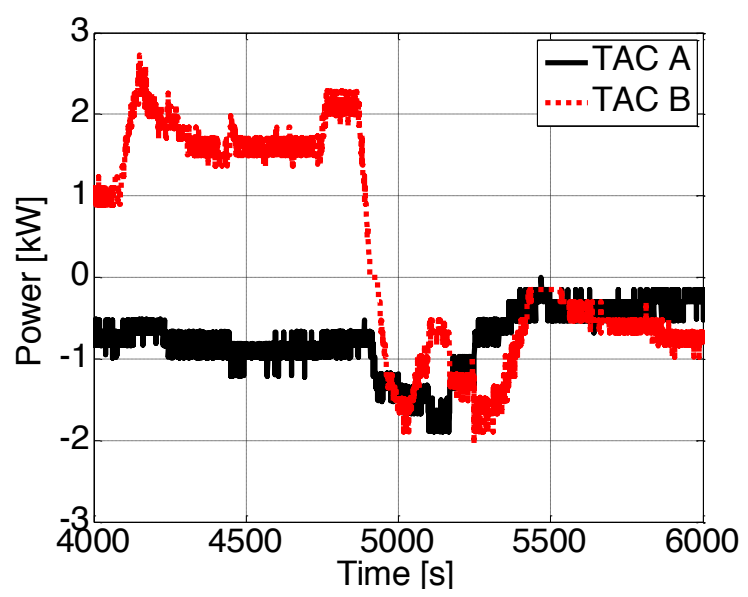

(d)

Figure 5 . System response to $100 \%$ reduction in power setting lasting approximately one minute and two minutes. (a) Low pressure response, (b) high pressure response, (c) transient source boundary temperatures and, (d) system net power generation response (negative power indicates power production from the system). 


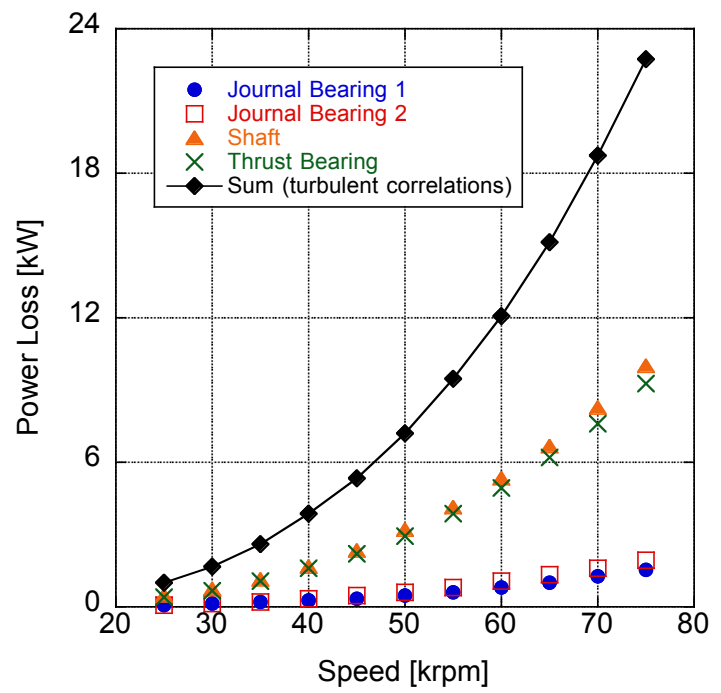

Figure 6. Breakdown of alternator windage losses for $\mathrm{CO}_{2}$ at $27^{\circ} \mathrm{C}$ and $1.4 \mathrm{MPa}$. Each data set was determined by using turbulent correlations and then summed to illustrate the relative contribution of the components. 


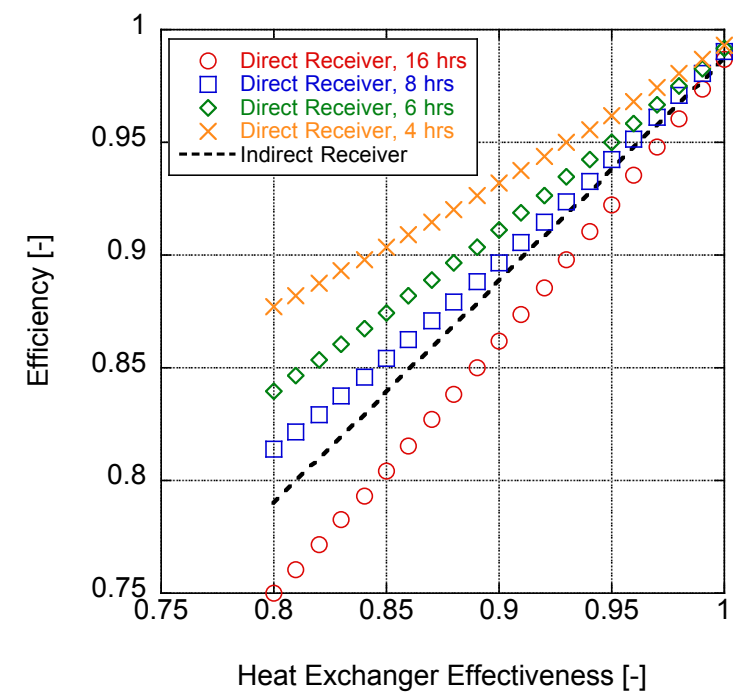

(a)

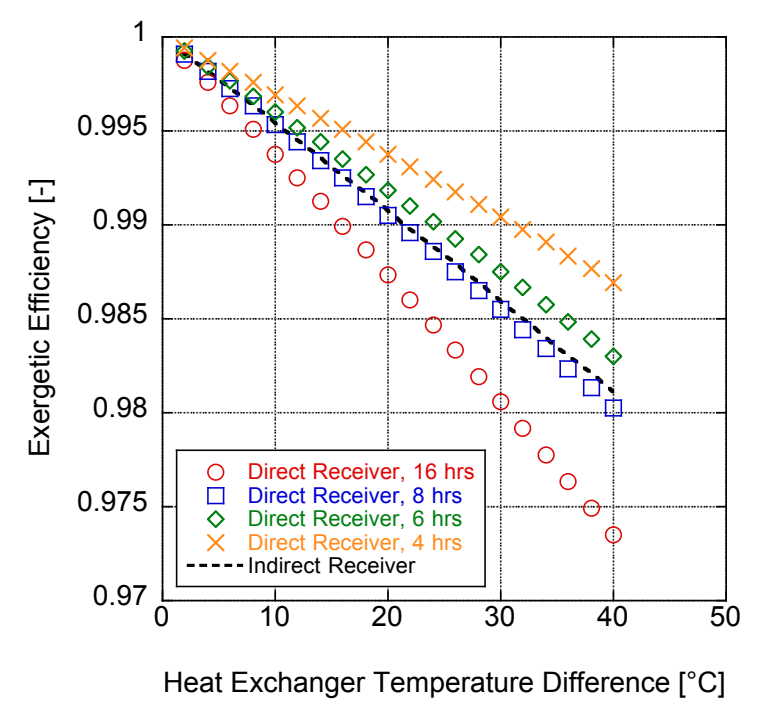

(b)

Figure 7. (a) First law efficiency as a function of heat exchanger (HX) effectiveness and (b) exergetic efficiency as a function of heat exchanger $\Delta \mathrm{T}$ for direct (e.g. $\mathrm{sCO}_{2}$ in receiver) and indirect (e.g. salt or secondary media in receiver) approaches for several storage capacities at $700{ }^{\circ} \mathrm{C}$, assuming a $98 \%$ storage efficiency and 8 hours of daylight operation. 